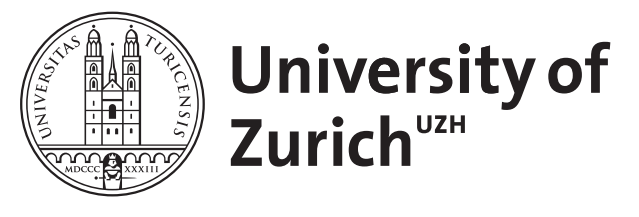

\title{
Competitive markets without commitment
}

\author{
Netzer, Nick ; Scheuer, Florian
}

\begin{abstract}
In the presence of a time-inconsistency problem with agency contracts, we show that competitive markets can implement allocations that Pareto-dominate those achieved by a benevolent government, and they induce more effort. We analyze a model with moral hazard and a two-sided lack of commitment. After agents have chosen their work, firms can modify contracts and agents can switch firms. If the ex post market outcome satisfies a weak notion of competitiveness and sufficiently separates individuals, it is Pareto superior to a government's allocation with a complete breakdown of incentives. Moreover, competitive markets without commitment implement more effort in equilibrium under general conditions.
\end{abstract}

DOI: https://doi.org/10.1086/658497

Posted at the Zurich Open Repository and Archive, University of Zurich ZORA URL: https://doi.org/10.5167/uzh-50642

Journal Article

Published Version

Originally published at:

Netzer, Nick; Scheuer, Florian (2010). Competitive markets without commitment. The Journal of Political Economy, 118(6):1079-1109.

DOI: https://doi.org/10.1086/658497 
Competitive Markets without Commitment

Author(s): Nick Netzer and Florian Scheuer

Reviewed work(s):

Source: Journal of Political Economy, Vol. 118, No. 6 (December 2010), pp. 1079-1109

Published by: The University of Chicago Press

Stable URL: http://www.jstor.org/stable/10.1086/658497

Accessed: 02/11/2011 10:13

Your use of the JSTOR archive indicates your acceptance of the Terms \& Conditions of Use, available at http://www.jstor.org/page/info/about/policies/terms.jsp

JSTOR is a not-for-profit service that helps scholars, researchers, and students discover, use, and build upon a wide range of content in a trusted digital archive. We use information technology and tools to increase productivity and facilitate new forms of scholarship. For more information about JSTOR, please contact support@jstor.org. 


\section{Competitive Markets without Commitment}

\section{Nick Netzer}

University of Zurich

\section{Florian Scheuer}

Stanford University

In the presence of a time-inconsistency problem with agency contracts, we show that competitive markets can implement allocations that Pareto-dominate those achieved by a benevolent government, and they induce more effort. We analyze a model with moral hazard and a two-sided lack of commitment. After agents have chosen their work, firms can modify contracts and agents can switch firms. If the ex post market outcome satisfies a weak notion of competitiveness and sufficiently separates individuals, it is Pareto superior to a government's allocation with a complete breakdown of incentives. Moreover, competitive markets without commitment implement more effort in equilibrium under general conditions.

\section{Introduction}

The question whether-and why-markets may perform better than governments has fascinated economists for a long time, at least since

We are grateful to the editor Robert Shimer, two anonymous referees, Daron Acemoglu, Carlos Alós-Ferrer, Abhijit Banerjee, Helmut Bester, Peter Diamond, Dennis Gaertner, Mike Golosov, Jon Gruber, Bard Harstad, Martin Hellwig, Casey Rothschild, Armin Schmutzler, Jean Tirole, Robert Townsend, Iván Werning, seminar participants at Arizona State University, Berlin, Bonn, Kellogg, London School of Economics, Massachusetts Institute of Technology, Princeton, University College London, University of California, Los Angeles, Wharton, Wisconsin School of Business, Zurich, the 2009 North American summer meetings of the Econometric Society at Boston University, the 2010 Allied Social Science Association meetings in Atlanta, and the 2010 Cowles Summer Macro Conference at Yale for valuable suggestions. All errors are our own. 
the work of Hayek (1945). However, despite the importance of this question for economics and beyond, it is still hard to find formal arguments for why markets may be able to outperform a benevolent government. Instead, the benchmark result is still provided by standard welfare theorems according to which a benevolent government can always replicate the market outcome or even improve on it if the market is affected by failures such as adverse selection or externalities. In this paper, we compare markets and governments and show that a government, even though benevolent and facing the same constraints as competitive firms, may not be able to replicate the market equilibrium, but instead implements an allocation that is Pareto dominated by the market outcome.

In particular, the market dominates even though it is affected by an adverse selection problem, overturning the classic justification for efficiency-enhancing government interventions in competitive markets. Market "failure" due to adverse selection is indeed a major argument in both the academic and political debates on markets versus governments. For instance, the need to provide mandatory social unemployment insurance is usually derived from the argument that private unemployment insurance markets would suffer from adverse selection and fail (Chiu and Karni 1998). In contrast, we point out that markets with adverse selection can outperform a government as they provide greater incentives to exert effort, for example, to find good jobs with low unemployment risk.

We consider a framework in which an adverse selection problem arises endogenously from a moral hazard problem with a lack of commitment. Ex ante, a risk-averse agent is able to affect the probability distribution over output by choosing some hidden action, and optimal contracts reflect a trade-off between providing incentives and insurance. However, such contracts are subject to a fundamental time-inconsistency problem: Whereas underinsurance is optimal ex ante so that the agent has incentives to exert effort, it becomes suboptimal once effort has been chosen but before output is realized. At this stage, the need to provide effort incentives has vanished, and a risk-neutral principal might find it optimal to provide the agent with full insurance. The agent, anticipating this, then would have incentives to exert the least costly effort level.

We examine how governments and competitive markets perform in the presence of this time-inconsistency problem. A benevolent government offers incentive contracts to a population of agents who differ in their privately known disutility of effort and is free to change them after agents have chosen their unobservable effort. We first show that, for a large class of benevolent governments, including utilitarian ones and those that aim at redistributing from agents who have taken high effort, 
and thus expect high output at the ex post stage, to low-effort, lowexpected output agents ex post, the unique equilibrium is such that no agent provides effort and everybody is fully insured, because the government will always implement an allocation that favors low-effort agents ex post, eliminating ex ante incentives. ${ }^{1}$

We then turn to the analysis of competitive markets, where contracts are offered by many risk-neutral firms and there is a two-sided lack of commitment: Firms can offer new contracts and modify their old contracts, and agents can switch to other firms once they have chosen effort. Hence, firms take the agents' effort decision and the composition of the population of agents as given at the ex post stage, and the moral hazard problem becomes a standard problem of adverse selection. While there are many ways to model competitive markets with adverse selection, suppose, for example, that the equilibrium in the ex post market results in the separating Rothschild and Stiglitz (1976) allocation. In anticipation of this outcome with separation and underinsurance, agents with low effort cost will find it optimal to provide high effort ex ante. Some incentives for effort provision can thus be sustained in contrast to the government's equilibrium allocation since the ex post adverse selection problem endogenously introduces commitment to refrain from full insurance and pooling.

Importantly, this result does not depend on the specifics of RothschildStiglitz contracts but turns out to be a robust implication of competition. We show that whenever the outcome of an ex post market satisfies a weak notion of competitiveness, called minimal contestability (Rothschild 2006), and it sufficiently separates agents who have taken different effort choices, it Pareto-dominates the government outcome. We provide a discussion of various circumstances-in addition to the standard Rothschild-Stiglitz setting-under which minimally contestable and separating allocations arise. We then focus on the Miyazaki-Wilson allocation, which includes the Rothschild-Stiglitz outcome as a special case and is well founded game-theoretically. We show that it satisfies our axioms so that the Pareto result applies. Also, it can be interpreted as the outcome that a government would choose that cares only about high-effort agents ex post and thus provides maximal incentives for effort ex ante. Whereas the Pareto comparison depends on the government being concerned about a welfare criterion that makes redistribution toward high-effort cost types desirable, we show on the basis of this insight that, for any distribution of Pareto weights that the government may use to evaluate

\footnotetext{
${ }^{1}$ The underlying mechanism relates to what has been described as the samaritan's dilemma (Buchanan 1975) or the problem of soft budget constraints (Kornai, Maskin, and Roland 2003).
} 
welfare, a Miyazaki-Wilson market still implements more effort than the government under general conditions.

Our formal model captures key characteristics of a variety of realworld allocation problems. For instance, the moral hazard problem can be interpreted as an individual's education decision with subsequent labor markets, as in Boadway, Marceau, and Marchand (1996) and Konrad (2001). Significant parts of education are private information and are typically completed before binding contracts with employers are signed. Even if there are contracts, as in the case of executive education, agents cannot be prevented from moving to other employers some time after their education has been completed, and employers are able to modify employment contracts or eventually lay off employees. The model captures exactly this setting of a two-sided lack of commitment.

Our analysis also applies to settings of insurance with ex ante moral hazard. For instance, workers can exert effort to reduce their risk of becoming unemployed by finding a job with low unemployment risk, patients may affect their risk of illness by undertaking a precautionary effort, and bankers may affect the risk of default of their loan portfolio by monitoring borrowers. Depending on the institutional framework, unemployment, health, or credit insurance is provided either through competitive markets or by the government, and both lack commitment. In particular, our model of markets captures a situation in which after preventive effort has been chosen but before the risk is realized, agents can switch insurers, taking along their private effort type such as their layoff risk, health, or quality of their loan portfolio, and insurance companies can modify contractual terms, resulting in an ex post adverse selection problem.

For all these applications, we can draw both positive and normative conclusions from our analysis. On the positive side, for instance, it predicts that private insurance markets generate more effort than government-provided social insurance systems in the presence of commitment problems. The reason is that governments cannot commit not to help the weak and poor at the ex post stage, whereas markets endogenously generate a form of commitment to refrain from full insurance and pooling.

Beyond this general implication, there are also more specific insights to be drawn from the model. For instance, it makes predictions about the equilibrium level of education and the form of employment contracts and, in particular, how they differ between competitive private firms and the public sector. There are several existing explanations for why private firms make use of explicit incentives more often than the public sector. ${ }^{2}$ It remains questionable, however, whether the lack of

\footnotetext{
${ }^{2}$ For instance, public-sector jobs might exhibit a multitask nature (Holmström and
} 
incentives in the public sector can indeed be considered as optimal (Burgess and Ratto 2003). Our model offers an explanation without making assumptions about exogenous differences between the public and the private sectors other than the difference in the implicit objective functions of governments and markets. As a consequence, the absence of high-powered incentives in the public sector is not interpreted as optimal.

On the normative side, our results have implications for market regulation. We emphasize that, for markets to be able to deal with the commitment problem successfully, firms must be allowed to offer separating contracts, some of which involve underinsurance and possibly strictly positive profits. These properties of the market equilibrium must not be regarded as a sign of market failure, and they do not provide support on their own for government interventions such as the provision of mandatory social insurance against unemployment or health risk, for instance. After having analyzed the model, we will return to these issues in Section IV.D, where we will relate our insights to recent proposals for regulating the markets for health and credit insurance.

The paper most closely related to ours is the seminal contribution by Fudenberg and Tirole (1990). They observe the same time-inconsistency problem in a principal-agent economy with a monopolistic profitmaximizing principal. In particular, after the monopolist has offered an initial contract and the agent has exerted effort, renegotiation occurs subject to the constraint that the agent cannot be made worse off than with the initial contract. The principal can therefore use the initial contract offer to affect the agent's reservation utility at the ex post renegotiation stage and thus to improve commitment. In contrast, we do not assume that initial contracts represent a constraint at the ex post stage, neither for a government nor for firms. The benevolent government maximizes some weighted sum of ex post utilities subject to a resource constraint rather than profits subject to a set of reservation utilities as in Fudenberg and Tirole's study. As for the market, we consider the case in which several profit-maximizing principals are competing and there is a two-sided lack of commitment: Firms are free to modify old contracts or offer new ones, possibly making some of their customers worse off than initially; agents in turn are free to obtain a contract from a competing firm. The necessity of randomization between effort levels in Fudenberg and Tirole's study is replaced in our model by the assumption of ex ante heterogeneity in effort costs.

Comparing the efficiency of markets and governments in a setting

Milgrom 1991), they might be affected by common agency problems (Dixit 1997), or they could be "mission oriented" and be occupied by intrinsically motivated agents (Besley and Ghatak 2005). 
without commitment, our paper shares a common goal with the contributions by Acemoglu, Golosov, and Tsyvinski (2008a, 2008b). However, their modeling of both markets and governments is quite different from the approach taken here. The provision of insurance contracts by private firms in competitive markets is ruled out, and government policies are distorted by political economy constraints. Moreover, their equilibria crucially rely on reputational concerns in an infinitely repeated game. In contrast, we completely abstract from reputational effects, assume a benevolent government, and consider markets in which competitive firms can offer insurance contracts that are restricted only by informational and commitment constraints.

Bisin and Rampini (2006) consider the performance of a government without commitment, comparing the cases in which agents can or cannot trade in anonymous markets. However, the time-inconsistency problem that they consider is different from the moral hazard problem analyzed here. It results from the flow of information that is revealed to the government through the agents' initial contract choices and is therefore an application of the ratchet effect. ${ }^{3}$ Markets are helpful in such a setting because they may reduce the information flow to the government and therefore its commitment problem. In contrast, we explicitly rule out commitment problems from a ratchet effect by assuming that ex post contract offers cannot be conditioned on initial contract choices. Instead, we focus on the time-inconsistency problem related to moral hazard and make predictions about how the commitment problem affects ex ante effort incentives.

Our results also complement a vast literature on public versus private provision of goods and services in an incomplete contracts world (see Shleifer [1998] for an overview). Whereas this literature focuses on how privatization affects the asymmetry of information or the production technology in a firm, we derive a clear advantage of competitive markets over a benevolent government without assuming any differences in the technological, informational, or commitment constraints faced by these different institutions. In contrast to Schmidt (1996) and Bisin and Rampini (2006), where privatization or the creation of anonymous markets, respectively, is assumed to conceal information from the government and to act as a constraint on the set of feasible policies, we show that the establishment of competitive markets can be interpreted as the choice of a specific, effort-prone welfare function. Thus, markets result in superior allocations compared to a government's allocation due to

\footnotetext{
${ }^{3}$ See Freixas, Guesnerie, and Tirole (1985) and Dewatripont (1989) for the standard treatments. Asheim and Nilssen (1996) study the consequences of such ratchet effect commitment problems for equilibrium in competitive insurance markets.
} 
the different objective function that they implicitly maximize, not due to a difference in the informational or commitment constraints.

Finally, our work relates to the literature on tax competition (e.g., Kehoe 1989; Conconi, Perroni, and Riezman 2008). In the case of capital taxation, this research has studied the effect of competition between countries on the time-inconsistency problem that results from the fact that capital taxes are highly distortive ex ante, but not ex post, after capital has been accumulated. The focus of this literature is on the optimal degree of cooperation between countries, facing a trade-off between disciplining effects of noncooperative behavior and an adverse race to the bottom.

The paper is structured as follows. Section II introduces our model economy. We then proceed to compare competitive equilibria without commitment to those achieved by a benevolent government with the same commitment problem. In Section III, we provide a comparison based on a general, axiomatic treatment of competitive market outcomes. In Section IV, we examine in greater detail some market outcomes that satisfy the axioms and are well founded game-theoretically. Section V presents conclusions.

\section{The Model}

We consider the following model economy. There is a continuum of risk-averse agents, indexed by the set $[0, \infty)$. Agents are expected utility maximizers with a Bernoulli utility function $U(c)$, where $c$ is consumption. The function $U(c)$ is twice continuously differentiable, with $U^{\prime}>$ 0 and $U^{\prime \prime}<0$. Following Fudenberg and Tirole (1990), we assume that both the domain and the range of $U$ are given by $\mathbb{R}$, so that $\lim _{c \rightarrow-\infty} U(c)=-\infty$ and $\lim _{c \rightarrow \infty} U(c)=\infty$. We also assume that the Inada condition $\lim _{c \rightarrow \infty} U^{\prime}(c)=0$ is satisfied. Let $\Phi(U)$ be the inverse function of $U$, which then satisfies $\Phi^{\prime}>0, \Phi^{\prime \prime}>0, \lim _{U \rightarrow-\infty} \Phi(U)=-\infty$, $\lim _{U \rightarrow \infty} \Phi(U)=\infty$, and $\lim _{U \rightarrow \infty} \Phi^{\prime}(U)=\infty$.

Each agent faces idiosyncratic risk with respect to the amount of consumption good that she produces for a principal. Production output can be either high, $y_{h}$, or low, $y_{l}$, with $y_{l}<y_{h}$. The probability of either output depends on the level of effort $e \in\{\underline{e}, \bar{e}\}$ that the agent has exerted. Since the ex ante moral hazard problem becomes a problem of adverse selection ex post, we say that an agent who chooses the high effort $\bar{e}$ becomes an ex post good type $(g)$, whereas an agent who chooses the low effort $\underline{e}$ becomes an ex post bad type $(b)$. Good types produce the high output $y_{h}$ with probability $p_{g}$ and bad types with probability $p_{b}$, where $0<p_{b}<p_{g}<1$ holds. In an insurance application, $y_{h}$ represents each agent's endowment, and $y_{h}-y_{l}$ is a possible damage that occurs with 
low probability $1-p_{g}$ for low risks (who have exerted preventive effort) and with larger probability $1-p_{b}$ for high risks.

The agents' preferences are assumed to be separable between consumption and effort, so that overall utility is given by $U(c)-H(e)$, where $H(e)$ denotes effort cost. We normalize $H(\underline{e})$ to zero. Agents differ in their disutility of effort $H(\bar{e})=d$, which is given by their index $d \in$ $[0, \infty)$ and which we refer to as their ex ante cost type. The composition of the population is described by a continuous distribution function $G$, defined on $\mathbb{R}$ with $G(d)=0$ for all $d \leq 0$. We adopt the convention of extending $G$ to $G(\infty)=1$ and we assume that $G$ has an associated density $g$ that satisfies $g(d)>0$ for all $d \in[0, \infty)$. Note that, throughout the paper, neither effort cost nor effort choice will be observable.

For our analysis it is convenient to operate in the utility space. In this space, a contract that a government or a firm offers to an agent is a tuple $\left(u_{h}, u_{l}\right) \in \mathbb{R}^{2}$ of consumption utilities that the agent obtains when producing the high and the low output, respectively. A contract allocation is a quadruple $\left(u_{b, h}, u_{b, l}, u_{g, h}, u_{g, l}\right) \in \mathbb{R}^{4}$, where $\left(u_{b, h}, u_{b, l}\right)$ is the contract intended for bad types and $\left(u_{g, h}, u_{g, l}\right)$ the one intended for good types.

In terms of the applications discussed above, the cost $d$ can be interpreted as an ex ante skill type, affecting the disutility of effort such as obtaining education, looking for a high-quality job, staying healthy, or monitoring borrowers. At the ex post stage, this then translates into an adverse selection problem with good and bad types, that is, individuals who differ in their privately known human capital or the quality of their job, patients who differ in their health status, or banks with different loan portfolios. Good types have the lower risk of being affected by the low outcome $y_{l}$, such as becoming unemployed, getting ill, or suffering defaults of loans. Insurance contracts specify payments and thus consumption utilities $u_{h}$ and $u_{l}$ contingent on these outcomes, which can be interpreted as a payment scheme for an employee or an insurance contract with a premium to be paid in case of the high outcome $y_{h}$ and an indemnity paid out when the bad outcome $y_{l}$ is realized.

\section{Markets versus Governments}

Throughout this section, we are concerned with the comparison between a benevolent government and competitive markets without commitment. We consider the government first in subsection A, followed by an axiomatic analysis of markets in subsection $\mathrm{B}$. 


\section{A. A Benevolent Government without Commitment}

Our first result, which predicts a complete breakdown of incentives for a large class of governments, is a generalization of an analogous result by Boadway et al. (1996) in the setting of education and taxation under a utilitarian government. We consider the following reduced timing:

Stage 1: Agents simultaneously choose their effort level.

Stage 2: The government announces a policy, that is, a set of two contracts.

Stage 3: Agents simultaneously choose between the offered contracts.

One could think of stage 1 being preceded by an additional stage in which the government announces an initial policy. Then the agents choose an effort level in anticipation of some final policy, possibly different from the announcement. If the government is not committed to its initial announcement, it is free to change the policy ex post, after effort choice has taken place (but remains unobservable). The initial announcement is then irrelevant, as captured by the reduced time structure. This argument assumes that initial announcements do not constitute binding reservation constraints to a government, as opposed to the monopolistic firm in Fudenberg and Tirole (1990).

In an insurance application, the policy could be an optimally designed social insurance arrangement, such as mandatory public health insurance in which individuals can choose between different levels of coverage. In an education and job market application, the policy describes the payment structure of jobs in the public sector, such as in schools or prisons (Hart, Shleifer, and Vishny 1997) or in other firms owned by the state (La Porta, Lopez-de-Silanes, and Shleifer 2002).

We solve the game backward. First, for any given unobservable effort choice in stage 1 and policy announcement in stage 2, each ex post type $k \in\{g, b\}$ selects the best contract in stage 3 , where we break ties in favor of the contract with a coverage closer to full insurance, that is, smaller absolute difference $\left|u_{h}-u_{l}\right|$. Stage 3 can then be eliminated by subsuming this choice into the government's payoff function. We can next derive the government's optimal policy at stage 2 when effort choices have been made. Observe first, however, that optimal effort choices in stage 1 must be of a threshold type in any equilibrium, with a critical value $\hat{d} \in \mathbb{R}_{0}^{+} \cup\{\infty\}$ such that the effort choice of ex ante type $d$ is given by $\bar{e}$ if $d<\hat{d}$ and by $\underline{e}$ if $d \geq \hat{d}$. Whenever an agent with effort cost $d$ finds it optimal to choose the high effort, in anticipation of some final policy, the same holds for any agent with $d^{\prime} \leq d$. Thus, in any equilibrium, agents with small effort cost $(d<\hat{d})$ choose the high effort 
and those with high effort cost $(d \geq \hat{d})$ choose the low effort, and the share of good types in the society becomes $G(\hat{d}) .{ }^{4}$

Suppose that the government has formed a correct belief about $\hat{d}$ and the share of good types $G(\hat{d})$. Let $\Psi(\hat{d})$ denote the relative weight placed on good types in the government's ex post welfare evaluation. For example, this weight equals the population share of good types for a utilitarian government, so that $\Psi(\hat{d})=G(\hat{d})$. In general, we can derive the whole ex post Pareto frontier and, by an appropriate choice of weights, can even capture governments that are concerned about effort directly or take into account individual effort costs in a nonseparable manner, as long as their implemented policy is ex post efficient. Then, whenever $\hat{d} \in(0, \infty)$ so that both ex post types exist, the benevolent government solves the following problem, which we refer to as program $\operatorname{BG}(\hat{d})$ :

$$
\begin{gathered}
\max _{\left(u_{b, h}, u_{b, b} u_{g, h}, u_{g, l}\right) \in \mathbb{R}^{4}} \Psi(\hat{d})\left[p_{g} u_{g, h}+\left(1-p_{g}\right) u_{g, l}\right] \\
+[1-\Psi(\hat{d})]\left[p_{b} u_{b, h}+\left(1-p_{b}\right) u_{b, l}\right]
\end{gathered}
$$

subject to the constraints

$$
\begin{gathered}
p_{g} u_{g, h}+\left(1-p_{g}\right) u_{g, l} \geq p_{g} u_{b, h}+\left(1-p_{g}\right) u_{b, l}, \\
p_{b} u_{b, h}+\left(1-p_{b}\right) u_{b, l} \geq p_{b} u_{g, h}+\left(1-p_{b}\right) u_{g, l}, \\
G(\hat{d})\left[p_{g} \Phi\left(u_{g, h}\right)+\left(1-p_{g}\right) \Phi\left(u_{g, l}\right)\right]+[1-G(\hat{d})]\left[p_{b} \Phi\left(u_{b, h}\right)\right. \\
\left.+\left(1-p_{b}\right) \Phi\left(u_{b, l}\right)\right] \leq R(\hat{d}) .
\end{gathered}
$$

The government maximizes a weighted average of the expected utilities of good and bad types subject to the two standard incentive constraints and the resource constraint. Here,

$$
R(\hat{d})=\left\{G(\hat{d}) p_{g}+[1-G(\hat{d})] p_{b}\right\} y_{h}+\left\{1-G(\hat{d}) p_{g}-[1-G(\hat{d})] p_{b}\right\} y_{l}
$$

are per capita resources. The following lemma characterizes the solution of this problem (see also, e.g., Bisin and Gottardi 2006).

Lemma 1. Fix any $\hat{d} \in(0, \infty)$. (i) $\operatorname{BG}(\hat{d})$ has a unique solution $V^{\mathrm{BG}}(\hat{d})=\left(u_{b, h}^{\mathrm{BG}}(\hat{d}), u_{b, l}^{\mathrm{BG}}(\hat{d}), u_{g, h}^{\mathrm{BG}}(\hat{d}), u_{g, l}^{\mathrm{BG}}(\hat{d})\right)$. (ii) If $\Psi(\hat{d}) \geq G(\hat{d})$, then $u_{b, h}^{\mathrm{BG}}(\hat{d})=u_{b, l}^{\mathrm{BG}}(\hat{d}) \equiv u_{b}^{\mathrm{BG}}(\hat{d})$ and $u_{g, h}^{\mathrm{BG}}(\hat{d}) \geq u_{g, l}^{\mathrm{BG}}(\hat{d})$. Furthermore,

$$
u_{b}^{\mathrm{BG}}(\hat{d})=p_{b} u_{g, h}^{\mathrm{BG}}(\hat{d})+\left(1-p_{b}\right) u_{g, l}^{\mathrm{BG}}(\hat{d}) \leq p_{g} u_{g, h}^{\mathrm{BG}}(\hat{d})+\left(1-p_{g}\right) u_{g, l}^{\mathrm{BG}}(\hat{d})
$$

holds. (iii) If $\Psi(\hat{d}) \leq G(\hat{d})$, then $u_{g, h}^{\mathrm{BG}}(\hat{d})=u_{g, l}^{\mathrm{BG}}(\hat{d}) \equiv u_{g}^{\mathrm{BG}}(\hat{d})$ and

\footnotetext{
${ }^{4}$ Since effort choice remains unobservable, we do not need to derive the government's optimal policy for effort choice profiles different from such threshold profiles, because deviations from an equilibrium candidate are not observed.
} 
$u_{b, l}^{\mathrm{BG}}(\hat{d}) \geq u_{b, h}^{\mathrm{BG}}(\hat{d})$. Furthermore,

$$
u_{g}^{\mathrm{BG}}(\hat{d})=p_{g} u_{b, h}^{\mathrm{BG}}(\hat{d})+\left(1-p_{g}\right) u_{b, l}^{\mathrm{BG}}(\hat{d}) \leq p_{b} u_{b, h}^{\mathrm{BG}}(\hat{d})+\left(1-p_{b}\right) u_{b, l}^{\mathrm{BG}}(\hat{d})
$$

holds.

Proof. See the Appendix.

Lemma 1 demonstrates how the government's optimal policy at the ex post stage depends on the Pareto weights assigned to ex post good and bad types. In particular, the ex post Pareto frontier can be decomposed in two parts: The first regime, characterized in part ii of the lemma, involves redistribution from bad to good types (as captured by $\Psi(\hat{d}) \geq G(\hat{d})$, so that the government attaches a larger weight to good types than their population share) and is therefore such that the bad types' incentive constraint (3) binds, the bad types obtain full insurance, and the good types partial insurance. The other regime, which arises if $\Psi(\hat{d}) \leq G(\hat{d})$ (part iii of the lemma), involves the opposite direction of redistribution ex post, from good to bad types. Therefore, the good types' incentive constraint (2) binds and they obtain full insurance and the bad types overinsurance. Clearly, good types obtain the higher ex post expected utility than bad types in the first regime and the lower one in the second regime. A special case arises when $\Psi(\hat{d})=G(\hat{d})$, and thus both types are weighted at their population share. Then, at the optimum, both types get full insurance and there is complete pooling: $u_{b, h}^{\mathrm{BG}}(\hat{d})=u_{b, l}^{\mathrm{BG}}(\hat{d})=u_{g, h}^{\mathrm{BG}}(\hat{d})=u_{g, l}^{\mathrm{BG}}(\hat{d})$. Note that, since the effort choice has already been taken, the government without commitment does not care about providing effort incentives with its policy at the ex post stage, but only about achieving optimal redistribution across the two ex post types.

If $\hat{d} \in\{0, \infty\}$, that is, if all agents are either good types or bad types, the government's problem $\mathrm{BG}(\hat{d})$ prescribes the utility maximization of the unique ex post type, subject to a resource constraint. First, resources will clearly be exhausted in the solution. Second, convexity of $\Phi$ implies that the solution entails an output-independent payment. Hence for $\hat{d} \in\{0, \infty\}$ we analogously define $V^{\mathrm{BG}}(\hat{d})$ by ${ }^{5}$

$$
u_{b, h}^{\mathrm{BG}}(\hat{d})=u_{b, l}^{\mathrm{BG}}(\hat{d})=u_{g, h}^{\mathrm{BG}}(\hat{d})=u_{g, l}^{\mathrm{BG}}(\hat{d})=U(R(\hat{d})) .
$$

Similarly to Fudenberg and Tirole (1990, definition 3.1), we now define an equilibrium with a benevolent government without commitment as follows.

Definition 1. An equilibrium with a benevolent government (EBG) is a pair $\left(d^{*}, V^{*}\right)$ where (i) $V^{*}=V^{\mathrm{BG}}\left(d^{*}\right)$ and (ii)

${ }^{5}$ We let $V^{\mathrm{BG}}(0)$ and $V^{\mathrm{BG}}(\infty)$ be elements of $\mathbb{R}^{4}$ for notational consistency, even though there is only one ex post type if $\hat{d} \in\{0, \infty\}$. One can still think of $\left(u_{k, h}^{\mathrm{BG}}(\hat{d}), u_{k, l}^{\mathrm{BG}}(\hat{d})\right)$ as the best contract for type $k \in\{g, b\}$ among those offered, even though only one type actually exists and the government offers a single contract only. 
1090

$$
d^{*}=p_{g} u_{g, h}^{\mathrm{BG}}\left(d^{*}\right)+\left(1-p_{g}\right) u_{g, l}^{\mathrm{BG}}\left(d^{*}\right)-p_{b} u_{b, h}^{\mathrm{BG}}\left(d^{*}\right)-\left(1-p_{b}\right) u_{b, l}^{\mathrm{BG}}\left(d^{*}\right) .
$$

If effort choice is described by some $\hat{d}$ and the government has formed a correct belief, it will implement $V^{\mathrm{BG}}(\hat{d})$ ex post. Condition ii captures that in stage 1 agents will anticipate this outcome, so that their actually optimal effort choice is described by the threshold

$$
D^{\mathrm{BG}}(\hat{d})=p_{g} u_{g, h}^{\mathrm{BG}}(\hat{d})+\left(1-p_{g}\right) u_{g, l}^{\mathrm{BG}}(\hat{d})-p_{b} u_{b, h}^{\mathrm{BG}}(\hat{d})-\left(1-p_{b}\right) u_{b, l}^{\mathrm{BG}}(\hat{d}) .
$$

This holds because each agent calculates her ex post utility from being a good type (choosing the good type's optimal contract) and the corresponding utility from being a bad type and compares the difference to her effort cost $d$. The function $D^{\mathrm{BG}}$ therefore yields the indifferent cost type given any threshold $\hat{d}$, and no agent has an incentive to deviate if and only if the fixed-point condition $d^{*}=D^{\mathrm{BG}}\left(d^{*}\right)$ and hence condition ii is satisfied.

Given the above results on the solution $V^{\mathrm{BG}}(\hat{d})$ for varying levels of $\hat{d} \in \mathbb{R}_{0}^{+} \cup\{\infty\}$, the following result is immediate.

Proposition 1. For any distribution of Pareto weights $\Psi,(0$, $\left.V^{\mathrm{BG}}(0)\right)$ is an EBG. It is the unique EBG if $\Psi \geqslant_{\text {FOSD }} G$.

If the government puts weakly overproportional weight on bad types ex post for any given $\hat{d}$, captured by $\Psi \geqslant_{\text {FOSD }} G$ (i.e., $\Psi$ weakly dominates $G$ in the sense of first-order stochastic dominance), continuation contracts are always such that the segment of the ex post Pareto frontier is attained, which is described in part iii of lemma 1. Since the government aims at redistributing from good to bad types at the ex post stage, bad types obtain the (weakly) higher continuation expected utility than good types, which of course eliminates any effort incentives from an ex ante perspective. If $\Psi \geqslant_{\text {FOSD }} G$ is not satisfied, the complete breakdown of incentives remains an equilibrium: If all agents choose the low effort, any government implements a full insurance allocation ex post. Additional EBG might, however, emerge in that case. We examine such equilibria in Section IV.

\section{B. Competitive Markets without Commitment}

We now turn to the case in which contracts are provided by competitive firms rather than by a benevolent government, and both firms and agents are unable to commit to contracts before the hidden effort choice. That is, we consider a time structure with a two-sided lack of commitment, where, after an initial phase of contract offers and agents' choices of contracts and effort, firms are free to alter their existing contracts and offer additional ones, whereas agents are free to abrogate their contract and choose a new one, possibly switching between firms.

As argued in the introduction, we do not allow the firms' new contract 
offers or modifications to be conditioned on an agent's initial choice of contract. In the first place, this allows us to isolate our commitment problem from ratchet effects (Freixas et al. 1985). Second, it captures the realistic scenario that firms can modify concluded contracts only if they do not target specific individuals. For instance, insurance contracts can contain clauses that give the firm the right to modify terms of the contract without discriminating between customers. The decision whether to accept or to opt out of the contract is then left to the insurant, as in our model. However, the insured person can often cancel the policy with relatively short notice. In an education application, longrun contracts that arrange the terms of employment before educational choices have been made often do not exist at all, yielding an equivalent game-theoretic structure:

Stage 1: Agents choose an effort level.

Stage 2: Some market game takes place, resulting in a set of offered contracts.

Stage 3: Agents simultaneously choose a contract.

The structure is exactly the same as for the government. In particular, we assume that ex ante contracts (if they exist) do not constitute binding reservation constraints, and therefore, we do not exogenously assume better commitment opportunities for private firms than for the government. Also, all assumptions about information and observability are as before.

The key here is that the comparison between markets and governments that we derive in the following does not require a detailed specification of the market game in stage 2, nor does it rest on the particular equilibrium notion for the ex post market. We assume only that, after agents have chosen their effort according to a threshold $\hat{d}$, firms form a correct belief about $\hat{d}$ and some ex post market game takes place, which results in an equilibrium set of contract offers. While the market game for given effort $\hat{d}$ could be complicated, with respect to the timing of moves or its observability assumptions, we restrict attention to its outcome, that is, to the two contracts among the final offers that maximize the utility of the two different effort types and will thus be chosen in stage 3 . We denote this outcome, for a fixed but yet unspecified ex post market game, by $V^{M}(\hat{d})=\left(u_{b, h}^{M}(\hat{d}), u_{b, l}^{M}(\hat{d}), u_{g, h}^{M}(\hat{d}), u_{g, l}^{M}(\hat{d})\right)$ and propose the following equilibrium definition, which is completely analogous to the EBG definition in subsection A.

Definition 2. An equilibrium with competitive markets (ECM) is a pair $\left(d^{*}, V^{*}\right)$ in which (i) $V^{*}=V^{M}\left(d^{*}\right)$ is the ex post market outcome given $d^{*}$ and (ii)

$$
d^{*}=p_{g} u_{g, h}^{M}\left(d^{*}\right)+\left(1-p_{g}\right) u_{g, l}^{M}\left(d^{*}\right)-p_{b} u_{b, h}^{M}\left(d^{*}\right)-\left(1-p_{b}\right) u_{b, l}^{M}\left(d^{*}\right) .
$$


We now proceed to formulate plausible conditions on the outcomes $V^{M}(\hat{d})$, which essentially require informational and resource feasibility as well as a minimal degree of competitive pressure. This approach builds on the insights of Rothschild (2006), who has observed a similar robustness property in a setting of categorical discrimination in insurance markets. In particular, we impose the following axioms.

(C1). $V^{M}(\hat{d})$ is incentive compatible, that is, $p_{k} u_{k, h}^{M}(\hat{d})+\left(1-p_{k}\right) u_{k, l}^{M}(\hat{d}) \geq p_{k} u_{k^{\prime}, h}^{M}(\hat{d})+\left(1-p_{k}\right) u_{k^{\prime}, l}^{M}(\hat{d}) \quad \forall k, k^{\prime} \in\{g, b\}$.

(C2). $V^{M}(\hat{d})$ is resource feasible, that is,

$$
\begin{gathered}
G(\hat{d})\left[p_{g} \Phi\left(u_{g, h}^{M}(\hat{d})\right)+\left(1-p_{g}\right) \Phi\left(u_{g, l}^{M}(\hat{d})\right)\right]+[1-G(\hat{d})]\left[p_{b} \Phi\left(u_{b, h}^{M}(\hat{d})\right)\right. \\
\left.+\left(1-p_{b}\right) \Phi\left(u_{b, l}^{M}(\hat{d})\right)\right] \leq R(\hat{d}) .
\end{gathered}
$$

(C3). $\quad V^{M}(\hat{d})$ is minimally contestable; that is, there does not exist an incentive-compatible outcome $\tilde{V}=\left(\tilde{u}_{b, h}, \tilde{u}_{b, l}, \tilde{u}_{g, h}, \tilde{u}_{g, l}\right)$ such that (1) $\pi_{k}\left(\tilde{u}_{k, h}, \tilde{u}_{k, l}\right) \geq 0$ for all $k \in\{g, b\}$ and $(2) \pi_{k}\left(\tilde{u}_{k, h}, \tilde{u}_{k, l}\right)>0$ and

$$
p_{k} \tilde{u}_{k, h}+\left(1-p_{k}\right) \tilde{u}_{k, l}>p_{k} u_{k, h}^{M}(\hat{d})+\left(1-p_{k}\right) u_{k, l}^{M}(\hat{d})
$$

for some $k \in\{g, b\}$, where

$$
\pi_{k}\left(u_{h}, u_{l}\right)=p_{k}\left[y_{h}-\Phi\left(u_{h}\right)\right]+\left(1-p_{k}\right)\left[y_{l}-\Phi\left(u_{l}\right)\right]
$$

are the profits earned with one unit of type $k$ agents in contract $\left(u_{h}\right.$, $\left.u_{l}\right)$.

Clearly, any market outcome $V^{M}(\hat{d})$ has to satisfy (C1) and (C2), irrespective of the exact structure of the market. The third requirement (C3), introduced by Rothschild (2006), formalizes the aforementioned minimal degree of competitive pressure. It precludes the existence of two incentive-compatible deviation contracts that make nonnegative profits whatever types they attract and strictly positive profits for at least one type who, at the same time, strictly prefers them to $V^{M}(\hat{d})$. This rules out market outcomes that do not survive even the slightest degree of competitive pressure. Again following Rothschild (2006), let us provide an example for an outcome $V^{M}(\hat{d})$ that satisfies conditions (C1)(C3).

Example.-Consider the Rothschild-Stiglitz contracts $\left(u_{g, h}^{\mathrm{RS}}, u_{g, l}^{\mathrm{RS}}\right)$ and $\left(u_{b}^{\mathrm{RS}}, u_{b}^{\mathrm{RS}}\right)$, where $u_{b}^{\mathrm{RS}}=U\left(p_{b} y_{h}+\left(1-p_{b}\right) y_{l}\right)$ is the output-independent payoff for bad types, and the good type's contract satisfies $\pi_{g}\left(u_{g, h}^{\mathrm{RS}}\right.$, $\left.u_{g, l}^{\mathrm{RS}}\right)=0$ and $p_{b} u_{g, h}^{\mathrm{RS}}+\left(1-p_{b}\right) u_{g, l}^{\mathrm{RS}}=u_{b}^{\mathrm{RS}}$. These contracts are independent of $\hat{d}$, and the outcome $V^{\mathrm{RS}}=\left(u_{b}^{\mathrm{RS}}, u_{b}^{\mathrm{RS}}, u_{g, h}^{\mathrm{RS}}, u_{g, l}^{\mathrm{RS}}\right)$ satisfies conditions (C1) and (C2) for any $\hat{d} \in(0, \infty)$ by definition. It also satisfies (C3) because $V^{\mathrm{RS}}$ simultaneously maximizes the utility of both types among the incentive-compatible pairs of contracts that break even individually.

The example illustrates that axioms (C1)-(C3) are actually weak. Even though the Rothschild-Stiglitz contracts might not be considered a rea- 
sonable market outcome for all $\hat{d} \in(0, \infty)$ (e.g., because of equilibrium nonexistence problems), they still satisfy the axioms. Also, we will later illustrate that the axioms do not rule out cross subsidization between ex post types, so that outcomes satisfying them might still be susceptible to cream-skimming behavior. But these considerations strengthen our following result, which is based on (C1)-(C3) only and will thus hold a fortiori for market outcomes that satisfy even stricter requirements. ${ }^{6}$

\section{A Comparison}

We will now compare markets based on properties (C1)-(C3) to a government as analyzed above. Our concept of Pareto dominance applies to ex ante utilities; that is, we say that an equilibrium Pareto-dominates another if it gives every agent (i.e., every ex ante cost type) a weakly larger and at least one a strictly larger overall utility, including effort cost. The effort level might be different for some types between the two equilibria.

Theorem 1. Any $\operatorname{ECM}\left(d^{*}, V^{*}\right)$ in which $d^{*} \in(0, \infty)$ and $V^{*}=$ $V^{M}\left(d^{*}\right)$ satisfies $(\mathrm{C} 1)-(\mathrm{C} 3)$ Pareto-dominates the EBG $\left(0, V^{\mathrm{BG}}(0)\right)$.

Proof.-Suppose that $V^{*}=V^{M}\left(d^{*}\right)$ satisfies (C1)-(C3). We first show that

$$
p_{k} u_{k, h}^{M}\left(d^{*}\right)+\left(1-p_{k}\right) u_{k, l}^{M}\left(d^{*}\right) \geq p_{k} U\left(y_{h}\right)+\left(1-p_{k}\right) U\left(y_{l}\right) \quad \forall k \in\{g, b\}
$$

must hold. Assume to the contrary that this is violated for a type $j \in$ $\{g, b\}$ and consider the outcome $\tilde{V}=\left(U\left(y_{h}\right)-\epsilon, U\left(y_{l}\right)-\epsilon, U\left(y_{h}\right)-\epsilon\right.$, $\left.U\left(y_{l}\right)-\epsilon\right)$ for small $\epsilon>0$. The outcome $\tilde{V}$ is incentive compatible and satisfies $\pi_{k}\left(U\left(y_{h}\right)-\epsilon, U\left(y_{l}\right)-\epsilon\right)>0$ for all $k \in\{g, b\}$ by definition. Also, for $\epsilon$ sufficiently small, we have that

$$
p_{j}\left[U\left(y_{h}\right)-\epsilon\right]+\left(1-p_{j}\right)\left[U\left(y_{l}\right)-\epsilon\right]>p_{j} u_{j, h}^{M}\left(d^{*}\right)+\left(1-p_{j}\right) u_{j, l}^{M}\left(d^{*}\right)
$$

still holds, so that $V^{*}=V^{M}\left(d^{*}\right)$ violates (C3), a contradiction. Thus any outcome that satisfies (C1)-(C3) must be individually rational as defined by Rothschild (2006).

Consider the Rothschild-Stiglitz contracts as introduced before. They satisfy $u_{g, h}^{\mathrm{RS}}>u_{g, l}^{\mathrm{RS}}$ and hence, since $p_{g}>p_{b}, p_{g} u_{g, h}^{\mathrm{RS}}+\left(1-p_{g}\right) u_{g, l}^{\mathrm{RS}}>u_{b}^{\mathrm{RS}}$. Lemma 13 in Rothschild (2006), considering the special case of only two types, now implies that $V^{M}\left(d^{*}\right)$ satisfies

${ }^{6}$ The axioms (C1)-(C3) coincide with those used by Rothschild (2006) except for two differences. First, in the definition of minimal contestability, Rothschild requires the deviation $\tilde{V}$ to be resource feasible, but this is implied by property 1 in the definition of (C3) and can be omitted. Second, in addition to (C1)-(C3), Rothschild also requires a market outcome to be individually rational, which amounts to the assumption that

$$
p_{k} u_{k, h}^{M}(\hat{d})+\left(1-p_{k}\right) u_{k, l}^{M}(\hat{d}) \geq p_{k} U\left(y_{h}\right)+\left(1-p_{k}\right) U\left(y_{l}\right) \quad \forall k \in\{g, b\} .
$$

As we show in the proof of theorem 1, this axiom is actually not independent; i.e., it is implied by (C1)-(C3) and can also be omitted. 


$$
p_{g} u_{g, h}^{M}\left(d^{*}\right)+\left(1-p_{g}\right) u_{g, l}^{M}\left(d^{*}\right) \geq p_{g} u_{g, h}^{\mathrm{RS}}+\left(1-p_{g}\right) u_{g, l}^{\mathrm{RS}}
$$

and

$$
p_{b} u_{b, h}^{M}\left(d^{*}\right)+\left(1-p_{b}\right) u_{b, l}^{M}\left(d^{*}\right) \geq u_{b}^{\mathrm{RS}}
$$

that is, both types are ex post weakly better off in $V^{M}\left(d^{*}\right)$ than in the Rothschild-Stiglitz contracts. Since $u_{b}^{\mathrm{RS}}=u^{\mathrm{BG}}(0)$ and $p_{g} u_{g, h}^{\mathrm{RS}}+(1-$ $\left.p_{g}\right) u_{g, l}^{\mathrm{RS}}>u_{b}^{\mathrm{RS}}=u^{\mathrm{BG}}(0)$, this implies that $V^{M}\left(d^{*}\right)$ ex post Pareto-dominates $V^{\mathrm{BG}}(0)$.

Condition ii in definition 2 then implies that

$$
\begin{gathered}
p_{g} u_{g, h}^{M}\left(d^{*}\right)+\left(1-p_{g}\right) u_{g, l}^{M}\left(d^{*}\right)-d>p_{b} u_{b, h}^{M}\left(d^{*}\right) \\
+\left(1-p_{b}\right) u_{b, l}^{M}\left(d^{*}\right) \geq u_{b}^{R S}=u^{\mathrm{BG}}(0)
\end{gathered}
$$

for all $d<d^{*}$, where the first inequality follows directly from condition ii in definition 2 and the other comparisons from the above argument for ex post Pareto dominance. Hence all agents who prefer the high effort $\left(d<d^{*}\right)$ and subsequently contract $\left(u_{g, h}^{M}\left(d^{*}\right), u_{g, l}^{M}\left(d^{*}\right)\right)$ in the ECM have a strictly larger utility, including effort cost, than they obtain as bad types in the EBG. Agents preferring low effort $\left(d \geq d^{*}\right)$ are weakly better off, from the above comparison. QED

We thus do not need to know exactly how markets work. The theorem shows that two properties of market equilibria are sufficient to make a Pareto comparison. First, the market has to be minimally contestable. Second, the market must be able to sustain some incentives for effort provision, captured by the assumption of an interior share of good types $d^{*} \in(0, \infty)$ in equilibrium. We have already illustrated the plausibility of minimal contestability in the previous section. To show that markets without commitment can actually be able to sustain incentives, we again consider the Rothschild-Stiglitz example.

Example continued.-Assume that $V^{M}(\hat{d})=V^{\mathrm{RS}}$ for all $\hat{d} \in(0, \infty)$. Since $V^{\mathrm{RS}}$ is separating with $p_{g} u_{g, h}^{\mathrm{RS}}+\left(1-p_{g}\right) u_{g, l}^{\mathrm{RS}}>u_{\hat{\mathrm{R}}}^{\mathrm{RS}}$, the optimal critical value for effort choice in anticipation of $V^{M}(\hat{d})=V^{\mathrm{RS}}, \Delta=p_{g} u_{g, h}^{\mathrm{RS}}+(1-$ $\left.p_{g}\right) u_{g, l}^{\mathrm{RS}}-u_{b}^{\mathrm{RS}}$, is strictly positive and independent of $\hat{d}$. Thus $\left(\Delta, V^{\mathrm{RS}}\right)$ is an ECM that satisfies the prerequisites of theorem 1.

The example illustrates that a sufficient degree of ex post separation for all $\hat{d} \in(0, \infty)$ is necessary to sustain incentives, which specifically requires that some separation is sustained as the share of good types goes to zero. Moreover, the separation has to be such that good types are better off ex post. For example, in regime iii from lemma 1 the government might also separate types, but bad types are better off, leading to a breakdown of incentives from an ex ante perspective. Correct ex post separation is indeed necessary to obtain an ECM in which good types do exist. But the existence of both types does not already guarantee that the allocation Pareto-dominates the government's outcome. If the minimal notion of competition as captured by (C3) is not 
satisfied by a separating outcome, we cannot expect it to be Pareto superior to $V^{\mathrm{BG}}(0)$. Consider, for example, a profit-maximizing monopolist that screens the population of agents ex post and extracts as many resources as possible. Then, even if there is an equilibrium in which both types do exist and are separated, the outcome will generally not leave both types better off than in $V^{\mathrm{BG}}(0)$. In fact, agents will be strictly worse off whenever their outside option is sufficiently unattractive. Hence, while our comparison between markets and governments does not depend on the details of the market game, it depends on the assumption that the market is competitive at least to some degree.

\section{The Implicit Redistributive Objective of Markets}

\section{A. Market Foundations}

The results in the previous section were based on axioms on market outcomes. We have illustrated them using the standard Rothschild-Stiglitz separating allocation. Unfortunately, as is well known, the Rothschild-Stiglitz equilibrium concept may run into nonexistence problems. However, there are various ways to overcome this problem. For instance, Riley (1979) has restored existence by considering a reactive equilibrium concept that involves deviators anticipating their competitors' reaction, and Bisin and Gottardi (2006) show that the Rothschild-Stiglitz separating allocation is always a Walrasian equilibrium when agents are restricted to trade incentive-compatible consumption bundles contingent on the states $h, l$. Similarly, Guerrieri, Shimer, and Wright (2010) demonstrate that the nonexistence problem vanishes in a setting with capacity constraints or search frictions.

Another problem with the Rothschild-Stiglitz equilibrium, even if it exists, is that it restricts firms to offer only one contract, ruling out cross subsidization and therefore leading to potential inefficiency. ${ }^{7}$ Since such a restriction is not imposed on our benevolent government, it may bias the comparison in favor of markets. Indeed, restricting the number of contracts that firms can offer amounts to a restriction of their ex post deviation possibilities, reducing the scope for profitable deviations from initial announcements and therefore increasing commitment. However, we demonstrate in Netzer and Scheuer (2009) that the comparison of markets and governments does not rely on such a restriction. In particular, we provide a game-theoretic foundation for the Miyazaki-Wilson equilibrium (Miyazaki 1977), which includes Rothschild-Stiglitz as a special case and is always Pareto efficient, by constructing an extensive form market game in which firms can offer any finite number of contracts

\footnotetext{
7 This assumption is shared by many approaches in the literature on competitive insurance markets, such as Wilson (1977) and Hellwig (1987).
} 
and in which a unique robust subgame-perfect equilibrium always exists. We show that the resulting equilibrium allocation is the solution to a maximization problem, which we characterize and discuss in the following. ${ }^{8}$

\section{B. Miyazaki-Wilson ECM}

Consider the contracts characterized by the following program, denoted by $\operatorname{MW}(\hat{d})$ :

$$
\max _{\left(u_{b, h}, u_{b, b}, u_{g, h}, u_{g}, t\right) \in \mathbb{R}^{4}} p_{g} u_{g, h}+\left(1-p_{g}\right) u_{g, l}
$$

subject to the constraints

$$
\begin{gathered}
p_{g} u_{g, h}+\left(1-p_{g}\right) u_{g, l} \geq p_{g} u_{b, h}+\left(1-p_{g}\right) u_{b, l}, \\
p_{b} u_{b, h}+\left(1-p_{b}\right) u_{b, l} \geq p_{b} u_{g, h}+\left(1-p_{b}\right) u_{g, l}, \\
G(\hat{d})\left[p_{g} \Phi\left(u_{g, h}\right)+\left(1-p_{g}\right) \Phi\left(u_{g, l}\right)\right]+[1-G(\hat{d})]\left[p _ { b } \Phi \left(u_{b, h}\right.\right. \\
\left.\left.+\left(1-p_{b}\right) \Phi\left(u_{b, l}\right)\right)\right] \leq R(\hat{d}), \\
\Phi\left(p_{b} u_{b, h}+\left(1-p_{b}\right) u_{b, l}\right) \geq p_{b} y_{h}+\left(1-p_{b}\right) y_{l} .
\end{gathered}
$$

In program MW $(\hat{d})$, the expected utility of good types is maximized under the ex post incentive compatibility constraints (6) and (7), the resource constraint (8), and a constraint (9) that requires the certainty equivalent of the bad types' contract to be at least as large as their expected endowment. This constraint makes sure that cross subsidization can go only from good to bad types in any solution because it implies that the resource cost of the bad types' contract must always be weakly larger than their expected output; that is, it earns zero or negative profits taken on its own. Note that, in a comparison with BG $(\hat{d})$, the only two differences are the additional constraint (9) and the objective function (5), which is a special case of (1) putting weight exclusively in good types.

Lemma 2. Fix any $\hat{d} \in(0, \infty)$. (i) $\operatorname{MW}(\hat{d})$ has a unique solution

$$
V^{\mathrm{MW}}(\hat{d})=\left(u_{b, h}^{\mathrm{MW}}(\hat{d}), u_{b, l}^{\mathrm{MW}}(\hat{d}), u_{g, h}^{\mathrm{MW}}(\hat{d}), u_{g, l}^{\mathrm{MW}}(\hat{d})\right) .
$$

(ii) $V^{\mathrm{MW}}(\hat{d})$ satisfies (C1)-(C3). Furthermore, $u_{b, h}^{\mathrm{MW}}(\hat{d})=u_{b, l}^{\mathrm{MW}}(\hat{d}) \equiv$ $u_{b}^{\mathrm{MW}}(\hat{d}), u_{g, h}^{\mathrm{MW}}(\hat{d})>u_{g, l}^{\mathrm{MW}}(\hat{d})$, and

${ }^{8}$ Bisin and Gottardi (2006) show that the Miyazaki-Wilson allocation can also be obtained in their setting if agents have to buy consumption rights in a separate Walrasian market before they can go to insurance markets and trade contingent consumption bundles there. 


$$
u_{b}^{\mathrm{MW}}(\hat{d})=p_{b} u_{g, h}^{\mathrm{MW}}(\hat{d})+\left(1-p_{b}\right) u_{g, l}^{\mathrm{MW}}(\hat{d})<p_{g} u_{g, h}^{\mathrm{MW}}(\hat{d})+\left(1-p_{g}\right) u_{g, l}^{\mathrm{MW}}(\hat{d}) .
$$

Proof. See the Appendix.

The problem characterizes the so-called Miyazaki-Wilson contracts. There are two cases depending on whether constraint (9) does or does not bind. If it does, each contract individually makes zero profits, and we obtain the classical Rothschild-Stiglitz outcome. Otherwise, the flat contract for bad types makes negative profits and the incentive contract for good types makes positive profits, implying cross subsidization from good to bad types. For completeness, we again briefly turn to the case in which $\hat{d} \in\{0, \infty\}$ and simply define $V^{\mathrm{MW}}(\hat{d})$ by

for $\hat{d} \in\{0, \infty\}$.

$$
u_{b, h}^{\mathrm{MW}}(\hat{d})=u_{b, l}^{\mathrm{MW}}(\hat{d})=u_{g, h}^{\mathrm{MW}}(\hat{d})=u_{g, l}^{\mathrm{MW}}(\hat{d})=U(R(\hat{d}))
$$

Now suppose that the ex post market actually leads to a MiyazakiWilson contract; that is, suppose that $V^{M}(\hat{d})=V^{\mathrm{MW}}(\hat{d})$ for all $\hat{d}$. Then, to characterize the set of equilibria of the complete game without commitment, called MW-ECM, we need to find the fixed points of the function

$$
D^{\mathrm{MW}}(\hat{d})=p_{g} u_{g, h}^{\mathrm{MW}}(\hat{d})+\left(1-p_{g}\right) u_{g, l}^{\mathrm{MW}}(\hat{d})-p_{b} u_{b, h}^{\mathrm{MW}}(\hat{d})-\left(1-p_{b}\right) u_{b, l}^{\mathrm{MW}}(\hat{d}),
$$

which gives us the indifferent ex ante cost type $D^{\mathrm{MW}}(\hat{d})$ if agents anticipate the final outcome $V^{\mathrm{MW}}(\hat{d})$. If $\hat{d} \in(0, \infty)$, we know from lemma 2 that $u_{b, h}^{\mathrm{MW}}(\hat{d})=u_{b, l}^{\mathrm{MW}}(\hat{d})=p_{b} u_{g, h}^{\mathrm{MW}}(\hat{d})+\left(1-p_{b}\right) u_{g, l}^{\mathrm{MW}}(\hat{d})$, so that we can simplify $D^{\mathrm{MW}}(\hat{d})$ to

$$
D^{\mathrm{MW}}(\hat{d})=\left(p_{g}-p_{b}\right)\left[u_{g, h}^{\mathrm{Mw}}(\hat{d})-u_{g, l}^{\mathrm{MW}}(\hat{d})\right] .
$$

Also, we immediately obtain $D^{\mathrm{Mw}}(0)=D^{\mathrm{Mw}}(\infty)=0$. Let us collect some useful properties of the function $D^{\mathrm{MW}}$ in the following lemma. These properties are based on comparative static effects of varying levels of $\hat{d}$ on the solution $V^{\mathrm{MW}}(\hat{d})$.

Lemma 3. (i) $D^{\mathrm{MW}}$ is continuous on $(0, \infty)$. (ii) $\lim _{\hat{d} \rightarrow 0} D^{\mathrm{MW}}(\hat{d})>0$ and $\lim _{\hat{d} \rightarrow \infty} D^{\mathrm{MW}}(\hat{d})=0$. (iii) If

$$
\frac{d}{d u} \frac{\Phi^{\prime \prime}(u)}{\Phi^{\prime}(u)} \geq 0
$$

there exists $\tilde{d} \in(0, \infty)$ such that $D^{\mathrm{MW}}(\hat{d})$ is flat on $(0, \tilde{d}]$ and strictly decreasing on $(\tilde{d}, \infty)$.

Proof. See Netzer and Scheuer (2009).

Properties i and ii together with $D^{\mathrm{MW}}(0)=0$ imply that, while $D^{\mathrm{MW}}$ is continuous otherwise, it has a discontinuity at $\hat{d}=0$. The reason is that a contract with output-independent utilities and hence no incentive for effort provision is the unique ex post outcome if $\hat{d}=0$, whereas for any positive $\hat{d}$ the good type's contract remains high powered. Specifically, we show in the proof of the lemma that (9) is binding in 


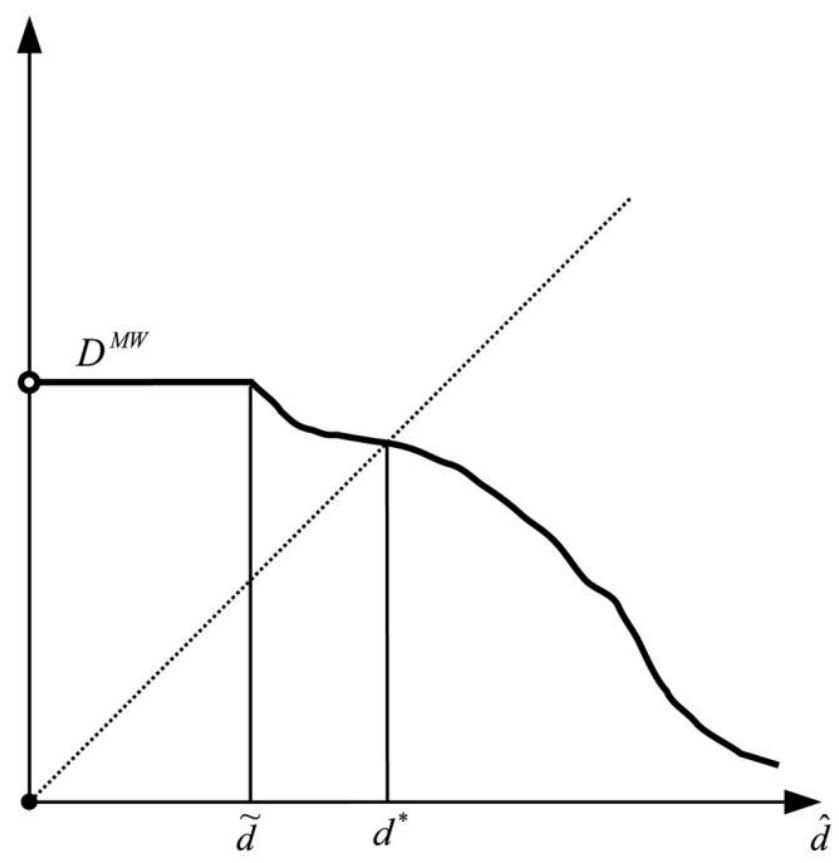

Fig. 1.-Fixed-point problem with Miyazaki-Wilson markets

$V^{\mathrm{Mw}}(\hat{d})$ for sufficiently small but positive $\hat{d}$, which is saying that the Rothschild-Stiglitz contracts obtain if the given share of good types is small. As $\hat{d} \rightarrow \infty$, however, the good type's contract converges to an output-independent, full-insurance contract, which requires cross subsidization to the bad types to preserve incentive compatibility. Condition (11) was introduced by Fudenberg and Tirole (1990). We show that, if it is satisfied, there is exactly one critical value $\tilde{d}$ at which the transition from zero to positive cross subsidization occurs, and an increase in $\hat{d}$ above $\tilde{d}$ leads to an increased subsidy and lower-powered incentives $u_{g, h}^{\mathrm{MW}}(\hat{d})-u_{g, l}^{\mathrm{MW}}(\hat{d})$ such that $D^{\mathrm{MW}}$ is strictly decreasing. Fudenberg and Tirole (1990) show that (11) is satisfied whenever risk aversion is not decreasing too quickly in income (see their lemma 3.2), for example, for constant relative risk aversion preferences with a coefficient of at least one. Figure 1 depicts the function $D^{\mathrm{MW}}(\hat{d})$ for such preferences. We can now state the main result of this subsection, which is a direct implication of the previous results and standard fixed-point theorems.

Proposition 2. (i) The pair $\left(0, V^{\mathrm{MW}}(0)\right)$ is an MW-ECM. (ii) There exists a value $d^{*}>0$ such that $\left(d^{*}, V^{\mathrm{MW}}\left(d^{*}\right)\right)$ is an MW-ECM. (iii) Under condition (11), there are no additional equilibria.

Clearly, $\hat{d}=0$ is always a fixed point of $D^{\mathrm{MW}}$, meaning that there is 
an MW-ECM in which no agent exerts effort and everyone obtains a contract with an output-independent payment. However, there always exists at least one other fixed point $d^{*}>0$ of $D^{\mathrm{MW}}$ and hence an MWECM in which a nonzero mass of agents exert the high effort. Since $D^{\mathrm{MW}}$ is weakly decreasing under condition (11), the positive fixed point is unique in this case. Otherwise, multiple nonzero fixed points and associated MW-ECM may exist.

\section{Comparing MW-ECM to EBG}

We are now in a position to compare market equilibria based on ex post Miyazaki-Wilson contracts to equilibria with a benevolent government. We will present two main results in this subsection. The first, theorem 2, compares welfare between the two types of equilibria. The second, theorem 3, compares the induced aggregate effort levels.

Theorem 2. Any MW-ECM $\left(d^{*}, V^{\mathrm{MW}}\left(d^{*}\right)\right)$ with $d^{*}>0$ ex ante Paretodominates the EBG $\left(0, V^{\mathrm{BG}}(0)\right)$, and strongly so if $V^{\mathrm{MW}}\left(d^{*}\right)$ satisfies (9) with slack.

Proof. We consider two cases, depending on whether constraint (9) is binding or not in $V^{\mathrm{MW}}\left(d^{*}\right)$. Assume first that it does, implying $u_{b}^{\mathrm{MW}}\left(d^{*}\right)=U\left(p_{b} y_{h}+\left(1-p_{b}\right) y_{l}\right)=u^{\mathrm{BG}}(0)$; that is, bad types in $V^{\mathrm{MW}}\left(d^{*}\right)$ obtain the same utility as all agents in $V^{\mathrm{BG}}(0)$, where nobody exerts any effort. By definition of $d^{*}$, we then have that

$$
p_{g} u_{g, h}^{\mathrm{MW}}\left(d^{*}\right)+\left(1-p_{g}\right) u_{g, l}^{\mathrm{MW}}\left(d^{*}\right)-d>u_{b}^{\mathrm{MW}}\left(d^{*}\right)=u^{\mathrm{BG}}(0)
$$

for all $d<d^{*}$. Given that $d^{*}$ is a fixed point of $D^{\mathrm{Mw}}$, the critical value $d^{*}$ determines optimal effort choice in $V^{\mathrm{MW}}\left(d^{*}\right)$, so that all good types in $V^{\mathrm{MW}}\left(d^{*}\right)$ are ex ante (including effort cost) strictly better off than they are as bad types in $V^{\mathrm{BG}}(0)$. If (9) is slack in $V^{\mathrm{MW}}\left(d^{*}\right)$, then $u_{b}^{\mathrm{MW}}\left(d^{*}\right)>u^{\mathrm{BG}}(0)$, and both low and bad types are ex ante strictly better off in $V^{\mathrm{MW}}\left(d^{*}\right)$, with the same argument. QED

The first part of theorem 2 is a corollary of previous results (although we present a convenient direct proof above): $V^{\mathrm{MW}}\left(d^{*}\right)$ satisfies (C1)(C3) according to lemma 2, so we can immediately apply our general theorem 1 to obtain the Pareto comparison. The second part of theorem 2 goes beyond the general insight of theorem 1 . If the market equilibrium involves cross subsidization from agents who choose to become good types to those who prefer to become bad types, as captured by slackness of (9), even all agents are strictly better off in the market than under a benevolent government.

The intuition for theorem 2 is that in the EBG $\left(0, V^{\mathrm{BG}}(0)\right)$ all agents end up being bad types in a contract with an output-independent payoff, equal in size to their expected output. In the market, only some agents remain bad types, obtaining a flat payment at the same or even a sub- 
sidized level, whereas the other agents prefer to become good types and choose a contract that makes them strictly better off. Hence it is the ex post adverse selection problem in competitive markets, leading to underinsurance of some agents, that is crucial for the dominance of markets over governments. Konrad (2001), in an extension of Boadway et al. (1996), compares the optimal tax policy of an informed to an uninformed utilitarian government and also finds that information rents due to ex post asymmetric information can sustain effort incentives and be Pareto improving. We emphasize, however, that we impose the same assumptions about information on both markets and the government, and, as opposed to Schmidt (1996), Konrad (2001) and Bisin and Rampini (2006) do not compare different information structures. From our perspective, establishing a competitive market can be interpreted as the delegation of decisions to a government that cares only for good types and faces the additional constraint (9). The similar idea that the creation of an independent agency and the subsequent delegation of decisions to this agency can be beneficial in the presence of a commitment problem is central to the research on central bank independence. In our model, the advantage of a market is that it acts as if it was a specific government, whereas individual firms are still maximizing their real objective (profits). This avoids incentive problems that would be present with an independent agency such as a central bank (Walsh 1995).

According to proposition $1,\left(0, V^{\mathrm{BG}}(0)\right)$ is always an EBG, and the unique one whenever the government is concerned about a utilitarian welfare criterion or aims at redistributing toward agents with high effort cost. If $\Psi \geqslant_{\text {FOSD }} G$ is not satisfied, then the welfare comparison in theorem 2 can become inapplicable because EBG with a positive share of good types might emerge. It is indeed not possible to make a general Pareto comparison between markets and government in that case. For instance, a government that cares almost only for low-effort cost agents might want to implement cross subsidization from bad to good types and thereby make bad types worse off than in an MW-ECM, where this direction of cross subsidization is impossible. However, we are now going to show that it is possible to compare the aggregate level of effort implemented by a government with a general distribution $\Psi$ of Pareto weights to that implemented by competitive markets. Despite the potential multiplicity of EBG, we still have the following result.

Theorem 3. Suppose that condition (11) is satisfied and the interior MW-ECM $\left(d^{*}, V^{\mathrm{MW}}\left(d^{*}\right)\right)$ satisfies $d^{*}>\tilde{d}$. Then $d^{*} \geq d^{* *}$ for any EBG $\left(d^{* *}, V^{\mathrm{BG}}\left(d^{* *}\right)\right)$.

Proof. See the Appendix.

According to the theorem, whenever condition (11) is satisfied and the MW-ECM involves cross subsidization, the associated equilibrium share of good types $G\left(d^{*}\right)$ is higher than the share of good types 
$G\left(d^{* *}\right)$ in any EBG, irrespective of the distribution of Pareto weights $\Psi$ that is used. Hence, in terms of incentives for effort, a benevolent government cannot do better than the market. The reason is again that Miyazaki-Wilson markets replicate an extreme government that cares only about ex post good types.

The restriction to the case in which the MW-ECM involves cross subsidization is necessary because, as argued above, our markets are constrained by the fact that there cannot be cross subsidization from bad to good types, whereas the government is not. A government that is otherwise similar to the market, in that it puts a large weight on good ex post types, may find it optimal to make these good types even better off, at the expense of bad types, which increases the incentive to exert effort. As proposition 1 makes clear, this can occur only if the government puts sufficiently overproportional welfare weight on low-effort cost types.

\section{Implications for Market Regulation}

The previous results have important implications for market regulation. They highlight that competitive firms must be allowed to offer separating contracts for markets to be able to implement allocations that dominate the government outcome. More important, the market equilibrium involves underinsurance for some agents, and it may require cross subsidization where firms use strictly positive profits that they earn with some contracts to finance the losses incurred with other contracts. All these three properties-separation, underinsurance, and cross subsidization-are crucial for the above results that markets sustain higher effort incentives than a government and that they implement an ex post Pareto-efficient outcome that (strictly) dominates the government's allocation.

These insights cast doubt on regulatory policies that aim at achieving standardization of contracts, reduce underinsurance, or enforce actuarial fairness of individual contracts. For instance, our model applies to the moral hazard problem that banks face in monitoring their loan portfolio and the time-inconsistency problem related to credit insurance. From an ex ante perspective, less than full credit insurance is optimal in order to incentivize banks to monitor their borrowers, but ex post, a private credit insurer or government may insure banks fully against the risk of default of their loan portfolio, for example, in the form of a bailout. Competitive credit insurance markets, as for instance in the form of a credit default swap market, stay away from full insurance because of the adverse selection problem at the ex post stage, where the quality of different banks' loan portfolios is private information. For this, however, it is important that more than one type of credit insurance 
contract can be traded in the market, notably that they can differ in the amount of coverage, and that they may not individually make zero profits in expectation. This is in contrast to recent discussions about reorganizing the credit default swap market (see, e.g., Stulz 2010). There, a popular proposal is to move away from an over-the-counter market with individualized contracts to exchange trading with standardized contracts, where actuarial fairness is mechanically enforced.

As far as there is a similar ex ante moral hazard problem in health insurance markets (see, e.g., Dave and Kaestner [2006] for evidence), the results also make clear that underinsurance and strictly positive profits of some insurance policies in competitive health insurance markets must not be viewed as signs of market failure, calling for regulatory intervention. Instead, they are key to sustain preventive incentives and achieve Pareto efficiency. Legal constraints on deductibles and coinsurance, as contained in the current U.S. health care reform bill, may, if binding, be detrimental to achieving these objectives. ${ }^{9}$

\section{Conclusion}

We have analyzed the performance of competitive markets in the framework of a time-inconsistency problem with incentive contracts. We have first pursued an axiomatic approach, based on weak properties that ex post market outcomes should satisfy to be considered competitive. We have shown that such outcomes Pareto-dominate the allocation that a large class of redistributive government can achieve, whenever markets are able to sustain some incentives for effort provision through separating agents ex post (theorem 1). We have then examined a specific but well-justified ex post market outcome in greater detail. If the ex post market produces Miyazaki-Wilson contracts, incentives for effort provision are preserved ex ante and our general Pareto result applies. It turns out that, in this case, the market replicates a benevolent government that cares only about high-effort agents and thus sustains maximal incentives for effort provision.

Our further results identify the level of cross subsidization between ex post types in the market as an important property to assess outcomes. First, the comparison between markets and governments becomes a strong Pareto dominance result whenever the market equilibrium entails cross subsidization (theorem 2). Second, even if the Pareto comparison is not applicable, because the government does not belong to the abovementioned class, we can still compare the aggregate equilibrium effort between market and government if the market cross-subsidizes. In that

${ }^{9}$ For a summary of the Patient Protection and Affordable Care Act, see the report of the Kaiser Family Foundation (2010). 
case, the market always performs better than a government in terms of incentives for effort (theorem 3). Altogether, our results suggest that competitive markets are an institution that is able to deal with the commitment problem very successfully, even in a model that excludes any reputational mechanisms.

Our model provides a transparent framework in which a benevolent government cannot replicate the outcome achieved by a market. This result is not due to exogenously assumed differences in technologies, commitment constraints, policy instruments, or information but is based solely on the different objectives that the two institutions pursue (implicitly, in the case of the market). To transparently expose the effect of competition on the commitment problem, we have ruled out reputational effects in our analysis. Future research on how competition and reputation interact may produce further interesting insights.

\section{Appendix}

\section{Proof of Lemma 1}

We prove the lemma by proving a sequence of preliminary claims. We suppress dependency on $\hat{d}$ for notational convenience.

ClaIm 1. Constraint (4) must be binding in any solution $V=\left(u_{b, h}\right.$, $\left.u_{b, l}, u_{g, h}, u_{g, t}\right)$ to BG.

Proof. Assume that $V$ satisfies all constraints and (4) with slackness. Consider $\tilde{V}=\left(u_{b, h}+\epsilon, u_{b, l}+\epsilon, u_{g, h}+\epsilon, u_{g, l}+\epsilon\right)$ for $\epsilon>0$. Then $\tilde{V}$ satisfies (2) and (3) and leads to a strictly increased value of (1). Continuity of $\Phi$ implies that (4) is still satisfied by $\tilde{V}$ for $\epsilon$ sufficiently small, so that $V$ was not a solution to BG.

Claim 2. Any solution $V$ must satisfy $u_{b, h}-u_{b, l} \leq u_{g, h}-u_{g, l}$.

Proof. Adding (2) and (3) yields, after rearranging, $\left(p_{g}-p_{b}\right)\left(u_{b, h}-u_{b, t}\right) \leq$ $\left(p_{g}-p_{b}\right)\left(u_{g, h}-u_{g, t}\right)$. Together with $p_{g}>p_{b}$, the claim follows.

Claim 3. Any solution $V$ must satisfy $u_{k, h}=u_{k, l}$ for at least one $k \in\{g, b\}$.

Proof. Suppose that the claim is not true and consider all possible cases. First, $0<u_{b, h}-u_{b, l} \leq u_{g, h}-u_{g, l}$ may hold. Define $\tilde{u}_{b}=p_{b} u_{b, h}+\left(1-p_{b}\right) u_{b, l}$ and consider $\tilde{V}=\left(\tilde{u}_{b}, \tilde{u}_{b}, u_{g, h}, u_{g, l}\right)$. By construction, $\tilde{V}$ satisfies (3), and the value of (1) is the same under $V$ and $\tilde{V}$. Since $p_{g}>p_{b}$ and $u_{b, h}>u_{b, l}$, it follows that

$$
p_{g} u_{b, h}+\left(1-p_{g}\right) u_{b, l}>p_{b} u_{b, h}+\left(1-p_{b}\right) u_{b, l}=\tilde{u}_{b}=p_{g} \tilde{u}_{b}+\left(1-p_{g}\right) \tilde{u}_{b}
$$

so that $\tilde{V}$ satisfies (2) as well, given that it is satisfied by $V$. Strict convexity of $\Phi$ implies that

$$
\begin{aligned}
p_{b} \Phi\left(u_{b, h}\right)+\left(1-p_{b}\right) \Phi\left(u_{b, l}\right) & >\Phi\left(p_{b} u_{b, h}+\left(1-p_{b}\right) u_{b, l}\right) \\
& =\Phi\left(\tilde{u}_{b}\right)=p_{b} \Phi\left(\tilde{u}_{b}\right)+\left(1-p_{b}\right) \Phi\left(\tilde{u}_{b}\right),
\end{aligned}
$$

so that $\tilde{V}$ satisfies (4) with slackness given $G \in(0,1)$. As in the proof of claim 1 , the value of (1) can then be increased above its value for $\tilde{V}$ and $V$, so that $V$ was not a solution. An analogous argument reveals that a solution cannot satisfy $u_{b, h}-u_{b, l} \leq u_{g, h}-u_{g, l}<0$. Assume finally that $u_{b, h}-u_{b, l}<0<u_{g, h}-u_{g, l}$. Define $\tilde{u}_{b}=p_{b} u_{b, h}+\left(1-p_{b}\right) u_{b, l}$ and $\tilde{u}_{g}=p_{g} u_{g, h}+\left(1-p_{g}\right) u_{g, l}$. If $\tilde{u}_{g}>\tilde{u}_{b}$, then $\tilde{V}=\left(\tilde{u}_{b}\right.$, 
$\left.\tilde{u}_{b}, u_{g, h}, u_{g, l}\right)$ satisfies all constraints but (4) with slackness, from the previous argument, so that $V$ was not a solution. The same holds for $\tilde{V}=\left(u_{b, h}, u_{b, l}, \tilde{u}_{g}, \tilde{u}_{g}\right)$ if $\tilde{u}_{g}<\tilde{u}_{b}$ and for $\tilde{V}=\left(\tilde{u}_{b}, \tilde{u}_{b}, \tilde{u}_{g}, \tilde{u}_{g}\right)$ if $\tilde{u}_{g}=\tilde{u}_{b}$.

Claim 4. Let $V$ be a solution to BG. If $u_{k, h}=u_{k, l} \equiv u_{k}$ for $k \in\{g, b\}$, then $u_{k}=p_{k} u_{j, h}+\left(1-p_{k}\right) u_{j, l}$ for $j \neq k$; that is, type $k$ 's incentive constraint is satisfied as an equality.

Proof. Suppose first that $u_{b, h}=u_{b, l} \equiv u_{b}$ but, to obtain a contradiction, $u_{b}>$ $p_{\sim} u_{g, h}+\left(1-p_{b}\right) u_{g, l}$. Incentive compatibility then implies $u_{g, l}<u_{g, h}$. Consider $\tilde{V}=\left(u_{b}, u_{b}, u_{g, h}-\epsilon, u_{g, l}+\epsilon \cdot\left(p_{g}\right) /\left(1-p_{g}\right)\right)$ for $\epsilon>0$. The value of (1) is the same under $\tilde{V}$ as under $V$ and (2) is still satisfied. For $\epsilon$ sufficiently small, (3) is also still satisfied by $\tilde{V}$, given slackness in $V$. Strict convexity of $\Phi$ immediately implies that (4) is slack in $\tilde{V}$, so that $V$ was not a solution to BG, as argued before. The case in which $u_{g, h}=u_{g, l}$ is proven analogously.

Claims 1-4 imply that any solution $V$ to BG must exhaust resources and satisfy either

$$
V \in \mathcal{I}_{1}=\left\{\left(u_{b, h}, u_{b, l}, u_{g, h}, u_{g, l}\right) \in \mathbb{R}^{4} \mid u_{b, h}=u_{b, l}=p_{b} u_{g, h}+\left(1-p_{b}\right) u_{g, l}, u_{g, l} \leq u_{g, h}\right\}
$$

or

$$
V \in \mathcal{I}_{2}=\left\{\left(u_{b, h}, u_{b, l}, u_{g, h}, u_{g, l}\right) \in \mathbb{R}^{4} \mid u_{g, h}=u_{g, l}=p_{g} u_{b, h}+\left(1-p_{g}\right) u_{b, l}, u_{b, l} \geq u_{b, h}\right\} .
$$

Observe that any $V \in \mathcal{I}_{1}$ automatically satisfies constraint (2) because $p_{g}>p_{b}$, and any $V \in \mathcal{I}_{2}$ satisfies (3). Hence we can formulate the program $\mathrm{BG}^{\prime}$, which has the same solutions as BG, as follows:

$$
\max _{\left(u_{b, h}, u_{b, b} u_{g, h}, u_{g, l}\right) \in \mathcal{I}_{1} \cup \mathcal{I}_{2}} \Psi\left[p_{g} u_{g, h}+\left(1-p_{g}\right) u_{g, l}\right]+(1-\Psi)\left[p_{b} u_{b, h}+\left(1-p_{b}\right) u_{b, l}\right]
$$

subject to

$$
G\left[p_{g} \Phi\left(u_{g, h}\right)+\left(1-p_{g}\right) \Phi\left(u_{g, l}\right)\right]+(1-G)\left[p_{b} \Phi\left(u_{b, h}\right)+\left(1-p_{b}\right) \Phi\left(u_{b, l}\right)\right]=R .
$$

Let $u^{\max }=U(R)$ and $V^{\max }=\left(u^{\max }, u^{\max }, u^{\max }, u^{\max }\right)$. It is immediate that $V^{\max } \in \mathcal{I}_{1}, V^{\max } \in \mathcal{I}_{2}$, and $V^{\max }$ satisfies (A2). Denote by $\mathrm{BG}_{1}^{\prime}$ the program given by (A1) and (A2) with the additional restriction that $V \in \mathcal{I}_{1}$ only and by $\mathrm{BG}_{2}^{\prime}$ the analogous program in which $V \in \mathcal{I}_{2}$.

Claim 5. $\mathrm{BG}_{1}^{\prime}$ has a unique solution $V_{1}$. It satisfies $V_{1}=V^{\max }$ if and only if $\Psi \leq G$.

Proof. Any solution to $\mathrm{BG}_{1}^{\prime}$ must be of the form $V=\left(u_{b}, u_{b}, u_{g, h}, u_{g, l}\right)$ with $u_{b}=p_{b} u_{g, h}+\left(1-p_{b}\right) u_{g, l}$ or, equivalently, $u_{g, l}=\left(u_{b}-p_{b} u_{g, h}\right) /\left(1-p_{b}\right)$. The condition $u_{g, h} \geq u_{g, l}$ can then be reformulated as $u_{g, h} \geq u_{b}$. We can therefore state the following modified problem $\mathrm{BG}_{1}^{\prime \prime}$, which has the same solutions as $\mathrm{BG}_{1}^{\prime}$ :

$$
\max _{\left(u_{g, h}, u_{b}\right) \mid u_{g, h} \geq u_{b}} \Psi\left[\left(\frac{1-p_{g}}{1-p_{b}}\right) u_{b}+\left(\frac{p_{g}-p_{b}}{1-p_{b}}\right) u_{g, h}\right]+(1-\Psi) u_{b}
$$

subject to

$$
G\left[p_{g} \Phi\left(u_{g, h}\right)+\left(1-p_{g}\right) \Phi\left(\frac{u_{b}-p_{b} u_{g, h}}{1-p_{b}}\right)\right]+(1-G) \Phi\left(u_{b}\right)=R .
$$

Denote the left-hand side of (A4) by $E\left(u_{g, h}, u_{b}\right)$. The function $E$ is continuously differentiable on $\mathbb{R}^{2}$, and straightforward calculations reveal that it is strictly 
increasing in $u_{g, h}$ whenever $u_{g, h} \geq u_{b}$, with $\lim _{u_{g, h} \rightarrow \infty} E\left(u_{g, h}, u_{b}\right)=\infty$ because of convexity. The function $E$ is strictly increasing in $u_{b}$ globally, with $\lim _{u_{b} \rightarrow-\infty}=-\infty$.

We first claim that $u^{\max }$ represents the largest possible choice of $u_{b}$. Consider the tuple $\left(u^{\max }, u^{\max }\right)$, which satisfies (A4) by definition. Any tuple $\left(\tilde{u}_{g, h}, \tilde{u}_{b}\right)$ with $\tilde{u}_{g, h} \geq \tilde{u}_{b}, \tilde{u}_{b}>u^{\max }$, and thus $\tilde{u}_{g, h}>u^{\max }$ can be reached from $\left(u^{\max }, u^{\max }\right)$ by first increasing $u_{g, h}$ from $u^{\max }$ to $\tilde{u}_{g, h}$ and then increasing $u_{b}$ from $u^{\max }$ to $\tilde{u}_{b}$. Both moves strictly increase $E\left(u_{g, h}, u_{b}\right)$, so that $\left(\tilde{u}_{g, h}, \tilde{u}_{b}\right)$ violates (A4), which proves the claim.

Now fix any $u_{b} \leq u^{\max }$. It follows that $E\left(u^{\max }, u_{b}\right) \leq E\left(u^{\max }, u^{\max }\right)=R$, with strict inequality whenever $u_{b}<u^{\max }$. Since $E\left(u_{g, h}, u_{b}\right)$ is strictly increasing in $u_{g, h}$ in the relevant range, with $\lim _{u_{g, h} \rightarrow \infty} E\left(u_{g, h}, u_{b}\right)=\infty$, it follows that there exists a unique value $H\left(u_{b}\right)$ such that $E\left(H\left(u_{b}\right), u_{b}\right)=R$, where $H\left(u_{b}\right) \geq u^{\max } \geq u_{b}$. The resulting function $H:\left(-\infty, u^{\max }\right] \rightarrow\left[u^{\max }, \infty\right)$ is continuously differentiable and thus continuous, by the implicit function theorem.

We can now reduce $\mathrm{BG}_{1}^{\prime \prime}$ to the one-dimensional problem

$$
\max _{u_{b} \mid u_{b} \leq u^{\max }}\left(1-\Psi \frac{p_{g}-p_{b}}{1-p_{b}}\right) u_{b}+\Psi \frac{p_{g}-p_{b}}{1-p_{b}} H\left(u_{b}\right) .
$$

We first claim that $H\left(u_{b}\right)$ is strictly concave. Let $\left(u_{g, h}^{\prime}, u_{b}^{\prime}\right)$ and $\left(u_{g, h}^{\prime \prime}, u_{b}^{\prime \prime}\right)$ satisfy $E\left(u_{g, h}^{\prime}, u_{b}^{\prime}\right)=E\left(u_{g, h}^{\prime \prime}, u_{b}^{\prime \prime}\right)=R$ and $\left(u_{g, h}^{\prime}, u_{b}^{\prime}\right) \neq\left(u_{g, h}^{\prime \prime}, u_{b}^{\prime \prime}\right)$. Define $u_{g, h}^{\prime \prime \prime}=\lambda u_{g, h}^{\prime}+(1-$ $\lambda) u_{g, h}^{\prime \prime}$ and $u_{b}^{\prime \prime \prime}=\lambda u_{b}^{\prime}+(1-\lambda) u_{b}^{\prime \prime}$ for $\lambda \in(0,1)$. Strict convexity of $\Phi$ then implies that $E\left(u_{g, h}^{\prime \prime \prime}, u_{b}^{\prime \prime \prime}\right)<R$, which in turn implies that

$$
\begin{aligned}
H\left(u_{b}^{\prime \prime \prime}\right) & =H\left(\lambda u_{b}^{\prime}+(1-\lambda) u_{b}^{\prime \prime}\right)>u_{g, h}^{\prime \prime \prime} \\
& =\lambda u_{g, h}^{\prime}+(1-\lambda) u_{g, h}^{\prime \prime} \\
& =\lambda H\left(u_{b}^{\prime}\right)+(1-\lambda) H\left(u_{b}^{\prime \prime}\right),
\end{aligned}
$$

which proves the claim. Second, implicit differentiation of (A4) reveals that $H$ is strictly decreasing with slope

$$
H^{\prime}\left(u_{b}\right)=\frac{G\left(1-p_{g}\right) \Phi^{\prime}\left(u_{g, l}\right)+(1-G)\left(1-p_{b}\right) \Phi^{\prime}\left(u_{b}\right)}{G\left(1-p_{g}\right) p_{b} \Phi^{\prime}\left(u_{g, l}\right)-G\left(1-p_{b}\right) p_{g} \Phi^{\prime}\left(u_{g, h}\right)},
$$

where $u_{g, h}=H\left(u_{b}\right)$ and $u_{g, l}$ has been resubstituted for $\left(u_{b}-p_{b} u_{g, h}\right) /\left(1-p_{b}\right)$. Observe that $\lim _{u_{b} \rightarrow-\infty} H^{\prime}\left(u_{b}\right)=0$. As $u_{b}$ decreases, $u_{g, h}=H\left(u_{b}\right)$ increases and $u_{g, l}$ decreases. Therefore, both terms in the numerator and the first term in the denominator of (A6) are decreasing as $u_{b}$ is decreasing (but they remain positive). Since $\lim _{u_{b} \rightarrow-\infty} E\left(u_{g, h}, u_{b}\right)=-\infty$, it follows that $\lim _{u_{b} \rightarrow-\infty} H\left(u_{b}\right)=\infty$, and thus the second term in the denominator of (A6) grows without bound as $u_{b} \rightarrow$ $-\infty$, because of the Inada condition $\lim _{u \rightarrow \infty} \Phi^{\prime}(u)=\infty$. Hence $\lim _{u_{b} \rightarrow-\infty} H^{\prime}\left(u_{b}\right)=$ 0 holds.

Strict concavity of $H\left(u_{b}\right)$ implies that the objective in (A5) is strictly concave whenever $\Psi>0$ and strictly increasing in $u_{b}$ if $\Psi=0$. Together with the fact that the objective must be strictly increasing in $u_{b}$ for sufficiently small values of $u_{b}$, because $\lim _{u_{b} \rightarrow-\infty} H^{\prime}\left(u_{b}\right)=0$ and $1-\Psi\left(p_{g}-p_{b}\right) /\left(1-p_{b}\right)>0$, this implies existence and uniqueness of a solution $V_{1}$.

We prove that $V_{1}=V^{\max }$ if and only if $\Psi \leq G$ by showing that the slope of the objective (A5) evaluated at $u_{b}=u^{\max }$ is (weakly) positive if and only if $\Psi \leq G$. The result then follows from strict concavity of $H\left(u_{b}\right)$ and $H\left(u^{\max }\right)=$ 
$u^{\max }$. Suppose $\Psi>0$. The respective condition then is

$$
1-\Psi \frac{p_{g}-p_{b}}{1-p_{b}}+\Psi \frac{p_{g}-p_{b}}{1-p_{b}} H^{\prime}\left(u^{\max }\right) \geq 0,
$$

and after we use $H\left(u^{\max }\right)=u^{\max }$ in (A6) and some rearrangements it follows that

$$
H^{\prime}\left(u^{\max }\right)=\frac{G\left(p_{g}-p_{b}\right)-\left(1-p_{b}\right)}{G\left(p_{g}-p_{b}\right)} .
$$

After substituting this in (A7), canceling terms, and using $p_{g}>p_{b}$, we obtain that (A7) is equivalent to $\Psi \leq G$. If $\Psi=0$, then (A5) is strictly increasing in $u_{b}$, and the claim follows immediately.

Claim 6. $\mathrm{BG}_{2}^{\prime}$ has a unique solution $V_{2}$. It satisfies $V_{2}=V^{\max }$ if and only if $\Psi \geq G$.

Proof. The proof is analogous to the proof of claim 5 and therefore is omitted.

Lemma 1 now follows. Since $V^{\max } \in \mathcal{I}_{1}$ and $V^{\max } \in \mathcal{I}_{2}$, whenever $V_{1} \neq$ $V^{\text {max }}=V_{2}$, then $V^{\mathrm{BG}}=V_{1} \in \mathcal{I}_{1}$ is the unique solution to the unrestricted problem $\mathrm{BG}^{\prime}$ and hence BG, satisfying all properties given in part ii. This is the case if and only if $\Psi>G$. Analogously, $V_{1}=V^{\max } \neq V_{2}$ implies $V^{\mathrm{BG}}=V_{2} \in \mathcal{I}_{2}$ and $V^{\mathrm{BG}}$ satisfies the properties given in part iii, which is the case if and only if $\Psi<G$. If $\Psi=G$, claims 5 and 6 immediately imply that $V^{\mathrm{BG}}=V^{\mathrm{max}}$, which satisfies the properties given in parts ii and iii.

\section{Proof of Lemma 2}

MW is a special case of BG for $\Psi=1$, with the additional constraint (9). Therefore, claims $1-4$ in the proof of lemma 1 apply unaltered, because none of the arguments is affected by (9).

Ignore constraint (9) and consider claim 6 above. It implies that $V_{2}=V^{\max }$ is the unique solution to $\mathrm{BG}_{2}^{\prime}$ because $\Psi=1 \geq G$. Since $V^{\max }$ obviously satisfies (9), it is also the unique solution when constraint (9) is imposed additionally. Then, since $V^{\max } \in \mathcal{I}_{1}$ as well, solutions $V^{\mathrm{MW}}$ to MW are identical to solutions of $\mathrm{BG}_{1}^{\prime}$ for $\Psi=1$ and under the additional constraint (9). Since any $V \in \mathcal{I}_{1}$ must be of the form $V=\left(u_{b}, u_{b}, u_{g, h}, u_{g, l}\right)$, (9) can be reformulated as $u_{b} \geq$ $U\left(p_{b} y_{h}+\left(1-p_{b}\right) y_{l}\right) \equiv u^{\min }$, where $u^{\min }<u^{\max }$ because $p_{b}<p_{g}$. Then, with the same arguments as for lemma 1, MW can be reformulated analogously to (A5) as

$$
u_{b}^{\mathrm{MW}}=\arg \max _{u_{b} \in\left[u^{\min }, u^{\max }\right]}\left(\frac{1-p_{g}}{1-p_{b}}\right) u_{b}+\left(\frac{p_{g}-p_{b}}{1-p_{b}}\right) H\left(u_{b}\right) .
$$

Existence and uniqueness of $V^{\mathrm{Mw}}$ now follow as before, with the additional simplification of a lower bound $u^{\min }$ on the choice of $u_{b}$. Also, the arguments for claim 5 above imply that $u_{b}^{\mathrm{MW}}<u^{\max }$ because $\Psi=1>G$ since $\hat{d} \in(0, \infty)$. This in turn implies $u_{g, l}^{\mathrm{MW}}<u_{b}^{\mathrm{MW}}<H\left(u_{b}^{\mathrm{MW}}\right)=u_{g, h}^{\mathrm{MW}}$, the second inequality from the results for claim 5 above and the first from incentive compatibility. This establishes the strict inequalities in lemma 2.

Conditions $(C 1)-(C 3)$.- To show that $V^{\mathrm{MW}}$ satisfies conditions (C1)-(C3), consider the Rothschild-Stiglitz contracts $V^{\mathrm{RS}}=\left(u_{b, h}^{\mathrm{RS}}, u_{b, l}^{\mathrm{RS}}, u_{g, h}^{\mathrm{RS}}, u_{g, l}^{\mathrm{RS}}\right)$, which solve 


$$
\max _{\left(u_{b, h}, u_{b, l} u_{g, h}, u_{g, l}\right) \in \mathbb{R}^{4}} p_{g} u_{g, h}+\left(1-p_{g}\right) u_{g, l}
$$

subject to the constraints

$$
\begin{gathered}
p_{k} u_{k, h}+\left(1-p_{k}\right) u_{k, l} \geq p_{k} u_{k^{\prime}, h}+\left(1-p_{k}\right) u_{k^{\prime}, l} \quad \forall k, k^{\prime} \in\{g, b\}, \\
G\left[p_{g} \Phi\left(u_{g, h}\right)+\left(1-p_{g}\right) \Phi\left(u_{g, l}\right)\right]+(1-G)\left[p_{b} \Phi\left(u_{b, h}\right)+\left(1-p_{b}\right) \Phi\left(u_{b, l}\right)\right] \leq R,
\end{gathered}
$$

and

$$
\Phi\left(p_{k} u_{k, h}+\left(1-p_{k}\right) u_{k, l}\right)=p_{k} y_{h}+\left(1-p_{k}\right) y_{l} \quad \forall k, k^{\prime} \in\{g, b\} .
$$

In a comparison with MW, this program involves the same objective function but a strictly smaller constraint set, implying $p_{g} u_{g, h}^{\mathrm{MW}}+\left(1-p_{g}\right) u_{g, l}^{\mathrm{MW}} \geq p_{g} u_{g, h}^{\mathrm{RS}}+$ $\left(1-p_{g}\right) u_{g, l}^{\mathrm{RS}}$. Moreover, constraint (9) in MW implies

$$
p_{b} u_{b, h}^{\mathrm{MW}}+\left(1-p_{b}\right) u_{b, l}^{\mathrm{MW}} \geq U\left(p_{b} y_{h}+\left(1-p_{b}\right) y_{l}\right)=p_{b} u_{b, h}^{\mathrm{RS}}+\left(1-p_{b}\right) u_{b, l}^{\mathrm{RS}} .
$$

Therefore, $V^{\mathrm{Mw}}$ weakly Pareto-dominates $V^{\mathrm{RS}}$. The result then follows from lemma 13 in Rothschild (2006).

\section{Proof of Theorem 3}

Fix a value $\hat{d} \in(0, \infty)$ and consider two cases. First, suppose that $\Psi(\hat{d}) \leq G(\hat{d})$. Then, arguing as for proposition 1 , we obtain $D^{\mathrm{BG}}(\hat{d}) \leq 0$. Second, consider the case $\Psi(\hat{d})>G(\hat{d})$. Lemma 1 implies that the unique solution to BG $(\hat{d})$ is such that constraint (3) holds with equality, $u_{b, h}^{\mathrm{BG}}(\hat{d})=u_{b, l}^{\mathrm{BG}}(\hat{d})$ and $u_{g, h}^{\mathrm{BG}}(\hat{d}) \geq u_{g, l}^{\mathrm{BG}}(\hat{d})$. From the fact that $p_{g}>p_{b}$, it then follows that (2) is automatically satisfied. Defining

$$
p(\hat{d}) \equiv p_{g} \Psi(\hat{d})+p_{b}[1-\Psi(\hat{d})],
$$

the solution must therefore be such that $\left(u_{g, h}^{\mathrm{BG}}(\hat{d}), u_{g, l}^{\mathrm{BG}}(\hat{d})\right)$ solves the simplified problem

$$
\max _{\left(u_{g, h} u_{g, l}\right) \mid u_{g, l} \leq u_{g, h}} p(\hat{d}) u_{g, h}+[1-p(\hat{d})] u_{g, l}
$$

subject to the resource constraint

$$
\begin{gathered}
G(\hat{d})\left[p_{g} \Phi\left(u_{g, h}\right)+\left(1-p_{g}\right) \Phi\left(u_{g, l}\right)\right] \\
+[1-G(\hat{d})] \Phi\left(p_{b} u_{g, h}+\left(1-p_{b}\right) u_{g, l}\right)=R(\hat{d}),
\end{gathered}
$$

which is binding as shown in the proof of lemma 1 . Suppose $\hat{d}>\tilde{d}$. First, for $\hat{d}=\infty, D^{\mathrm{BG}}(\hat{d})=D^{\mathrm{MW}}(\hat{d})=0$ holds. Otherwise, if $\hat{d} \in(\tilde{d}, \infty)$, by lemma 2 the outcome $V^{\mathrm{MW}}(\hat{d})$ is such that $\left(u_{g, h}^{\mathrm{MW}}(\hat{d}), u_{g, l}^{\mathrm{Mw}}(\hat{d})\right)$ solves

$$
\max _{\left(u_{g, h}, u_{g, l}\right) \mid u_{g, l} \leq u_{g, h}} p_{g} u_{g, h}+\left(1-p_{g}\right) u_{g, l}
$$

subject to the same budget constraint (A11) because (9) does not bind for $\hat{d}>\tilde{d}$ as shown in the proof of lemma 3 . Since (A11) is a convex constraint by the proof of lemma 1 and $p(\hat{d}) \leq p_{g}$ holds by (A9), the solutions $\left(u_{g, h}^{\mathrm{BG}}(\hat{d}), u_{g, l}^{\mathrm{BG}}(\hat{d})\right)$ and $\left(u_{g, h}^{\mathrm{MW}}(\hat{d}), u_{g, l}^{\mathrm{MW}}(\hat{d})\right)$ must be such that

$$
u_{g, h}^{\mathrm{BG}}(\hat{d}) \leq u_{g, h}^{\mathrm{MW}}(\hat{d}) \quad \text { and } \quad u_{g, l}^{\mathrm{BG}}(\hat{d}) \geq u_{g, l}^{\mathrm{MW}}(\hat{d}) .
$$


This implies

$$
\begin{aligned}
D^{\mathrm{BG}}(\hat{d}) & =\left(p_{g}-p_{b}\right)\left[u_{g, h}^{\mathrm{BG}}(\hat{d})-u_{g, l}^{\mathrm{BG}}(\hat{d})\right] \\
& \leq\left(p_{g}-p_{b}\right)\left[u_{g, h}^{\mathrm{MW}}(\hat{d})-u_{g, l}^{\mathrm{MW}}(\hat{d})\right] \\
& =D^{\mathrm{MW}}(\hat{d}) .
\end{aligned}
$$

Under property (11) and $d^{*}>\tilde{d}$, the function $D^{\mathrm{MW}}$ is strictly decreasing in $\hat{d}$ above its unique interior fixed point $d^{*}$, so that $D^{\mathrm{MW}}(\hat{d})<\hat{d}$ for all $\hat{d}>d^{*}$. Together with (A13) and $D^{\mathrm{BG}}(\infty)=D^{\mathrm{MW}}(\infty)=0$, this implies $D^{\mathrm{BG}}(\hat{d}) \leq D^{\mathrm{MW}}(\hat{d})<$ $\hat{d}$ for all $\hat{d}>d^{*}$, so that any fixed point $d^{* *}$ of $D^{\mathrm{BG}}$ must satisfy $d^{* *} \leq d^{*}$.

\section{References}

Acemoglu, Daron, Mikhail Golosov, and Aleh Tsyvinski. 2008a. "Markets versus Governments.” J. Monetary Econ. 55:159-89.

— 2008b. "Political Economy of Mechanisms." Econometrica 76:619-41.

Asheim, Geir, and Tore Nilssen. 1996. "Non-discriminating Renegotiation in a Competitive Insurance Market.” European Econ. Rev. 40:1717-36.

Besley, Timothy, and Maitreesh Ghatak. 2005. "Competition and Incentives with Motivated Agents." A.E.R. 95:616-36.

Bisin, Alberto, and Piero Gottardi. 2006. "Efficient Competitive Equilibria with Adverse Selection.” J.P.E. 114:485-516.

Bisin, Alberto, and Adriano Rampini. 2006. "Markets as Beneficial Constraints on the Government." J. Public Econ. 90:601-29.

Boadway, Robin, Nicolas Marceau, and Maurice Marchand. 1996. "Investment in Education and the Time Inconsistency of Redistributive Tax Policy." Economica 63:171-89.

Buchanan, James. 1975. "The Samaritan's Dilemma.” In Altruism, Morality and Economic Theory, edited by Edmund Phelps, 71-85. New York: Sage Found.

Burgess, Simon, and Marisa Ratto. 2003. "The Role of Incentives in the Public Sector: Issues and Evidence." Oxford Rev. Econ. Policy 19:285-300.

Chiu, W. Henry, and Edi Karni. 1998. "Endogenous Adverse Selection and Unemployment Insurance.” J.P.E. 106:806-27.

Conconi, Paola, Carlo Perroni, and Raymond Riezman. 2008. "Is Partial Tax Harmonization Desirable?” J. Public Econ. 92:254-67.

Dave, D., and R. Kaestner. 2006. "Health Insurance and Ex Ante Moral Hazard: Evidence from Medicare.” Manuscript, Univ. Illinois.

Dewatripont, Matthias. 1989. "Renegotiation and Information Revelation over Time: The Case of Optimal Labor Contracts.” Q.J.E. 104:589-620.

Dixit, Avinash. 1997. "Power of Incentives in Private versus Public Organizations." A.E.R. Papers and Proc. 87:378-82.

Freixas, Xavier, Roger Guesnerie, and Jean Tirole. 1985. "Planning under Incomplete Information and the Ratchet Effect." Rev. Econ. Studies 52:173-91.

Fudenberg, Drew, and Jean Tirole. 1990. "Moral Hazard and Renegotiation in Agency Contracts." Econometrica 58:1279-1320.

Guerrieri, Veronica, Robert Shimer, and Randall Wright. 2010. "Adverse Selection in Competitive Search Equilibrium.” Econometrica 78:1823-62.

Hart, Oliver, Andrei Shleifer, and Robert W. Vishny. 1997. "The Proper Scope of Government: Theory and an Application to Prisons." Q.J.E. 112:1127-61. 
Hayek, Friedrich A. 1945. "The Use of Knowledge in Society." A.E.R. 35:51930.

Hellwig, Martin. 1987. "Some Recent Developments in the Theory of Competition in Markets with Adverse Selection.” European Econ. Rev. 31:319-25.

Holmström, Bengt, and Paul Milgrom. 1991. "Multitask Principal-Agent Analyses: Incentive Contracts, Asset Ownership, and Job Design.” J. Law, Econ., and Org. 7:24-52.

Kaiser Family Foundation. 2010. "Summary of Patient Protection and Affordability Act." http://www.kff.org/healthreform/8061.cfm.

Kehoe, Patrick. 1989. "Policy Cooperation among Benevolent Governments May Be Undesirable." Rev. Econ. Studies 56:289-96.

Konrad, Kai. 2001. "Privacy and Time-Consistent Optimal Labor Income Taxation.” J. Public Econ. 79:503-19.

Kornai, János, Eric Maskin, and Gérard Roland. 2003. "Understanding the Soft Budget Constraint.” J. Econ. Literature 41:1095-1136.

La Porta, Rafael, Florencio Lopez-de-Silanes, and Andrei Shleifer. 2002. "Corporate Ownership around the World." J. Finance 54:471-517.

Miyazaki, Hajime. 1977. "The Rat Race and Internal Labor Markets." Bell J. Econ. 8:394-418.

Netzer, Nick, and Florian Scheuer. 2009. "Competitive Markets without Commitment.” Discussion Paper no. 0814, Univ. Zurich, Socioeconomic Inst.

Riley, John. 1979. "Informational Equilibrium.” Econometrica 47:331-59.

Rothschild, Casey. 2006. "Essays on Insurance Markets." PhD diss., Massachusetts Inst. Tech.

Rothschild, Michael, and Joseph Stiglitz. 1976. "Equilibrium in Competitive Insurance Markets: An Essay on the Economics of Imperfect Information." Q.J.E. 90:629-49.

Schmidt, Klaus. 1996. "The Costs and Benefits of Privatization: An Incomplete Contracts Approach." J. Law, Econ., and Org. 12:1-24.

Shleifer, Andrei. 1998. "State versus Private Ownership.” J. Econ. Perspectives 12: 133-50.

Stulz, Rene. 2010. "Credit Default Swaps and the Credit Crisis." J. Econ. Perspectives 24:73-92.

Walsh, Carl E. 1995. "Optimal Contracts for Central Bankers.” A.E.R. 85:15067.

Wilson, Charles A. 1977. "A Model of Insurance Markets with Incomplete Information.” J. Econ. Theory 12:167-207. 